\title{
Earthquake Swarm Detection Along the Hikurangi Trench, New Zealand: Insights Into the Relationship Between Seismicity and Slow Slip Events
}

\section{AUTHOR(S):}

Nishikawa, Tomoaki; Nishimura, Takuya; Okada, Yutaro

\section{CITATION:}

Nishikawa, Tomoaki ...[et al]. Earthquake Swarm Detection Along the Hikurangi Trench, New Zealand: Insights Into the Relationship Between Seismicity and Slow Slip Events. Journal of Geophysical Research: Solid Earth 2021, 126(4): e2020JB020618.

\section{ISSUE DATE:}

2021-04

URL:

http://hdl.handle.net/2433/267476

\section{RIGHT:}

(c) 2021. American Geophysical Union. All Rights Reserved.; The full-text file will be made open to the public on 06 October 2021 in accordance with publisher's 'Terms and Conditions for Self-Archiving'. 


\section{JGR Solid Earth}

\section{RESEARCH ARTICLE \\ 10.1029/2020JB020618 \\ Special Section: \\ Earthquake Swarm Detection Along the Hikurangi Trench, New Zealand: Insights Into the Relationship Between Seismicity and Slow Slip Events}

Creep on continental faults

and subduction zones:

Geophysics, geology, and

mechanics

\section{Key Points:}

- We detected earthquake swarms in the Hikurangi Trench, New Zealand, and compared them with slow slip events (SSEs) and tectonic tremors

- Twelve of 49 earthquake swarms associated with transient eastward GNSS displacements caused by SSEs preceded the displacements by 5-25 days

- These pre-SSE earthquake swarms might be triggered by intraplate fluid migration before the SSEs and not by SSE-induced stress loading

Supporting Information:

- Supporting Information S1

Correspondence to:

T. Nishikawa,

nishikawa.tomoaki.68s@st.kyoto-u. ac.jp

Citation

Nishikawa, T., Nishimura, T., \& Okada, Y. (2021). Earthquake swarm detection along the Hikurangi Trench, New

Zealand: Insights into the relationship between seismicity and slow slip events. Journal of Geophysical Research: Solid Earth, 126, e2020JB020618. https://doi. org/10.1029/2020JB020618

Received 17 JUL 2020

Accepted 3 FEB 2021

(C) 2021. American Geophysical Union. All Rights Reserved.

\author{
Tomoaki Nishikawa $^{1}$ (D), Takuya Nishimura ${ }^{1}$ (D), and Yutaro Okada ${ }^{2}$ (D) \\ ${ }^{1}$ Disaster Prevention Research Institute, Kyoto University, Kyoto, Japan, ${ }^{2}$ Graduate School of Science, Kyoto University, \\ Kyoto, Japan
}

\begin{abstract}
Earthquake swarms, which are anomalous increases in the seismicity rate without a distinguishable mainshock, often accompany transient aseismic processes, such as fluid migration and episodic aseismic slip along faults. Investigations of earthquake swarm activity can provide insights into the causal relationship between aseismic processes and seismicity. Slow slip events (SSEs) along the plate interface in the Hikurangi Trench, New Zealand, are often accompanied by intensive earthquake swarms. However, the detailed spatiotemporal distribution of these earthquake swarms is still unclear. Here, we use the epidemic-type aftershock-sequence (ETAS) model to detect earthquake swarms $(M \geq 3)$ and create a new earthquake swarm catalog (1997-2015) along the Hikurangi Trench. We compare the earthquake swarm catalog with Global Navigation Satellite System (GNSS) time series data, and existing SSE and tectonic tremor catalogs. Most of the detected (119) earthquake swarm sequences were intraplate events, and their epicenters were mainly concentrated along the east coast of the North Island, whereas many tectonic tremors were located inland. Twenty-five of the detected earthquake swarms occurred within 25 days before and after transient eastward GNSS displacements due to known or newly detected SSEs. We find that the earthquake swarms sometimes preceded the GNSS displacements by more than several days. SSE-induced stress loading is therefore not a plausible triggering mechanism for these pre-SSE earthquake swarms. We propose that high fluid pressure within the slab, which accumulated before the SSEs, may have caused intraplate fluid migration, which in turn triggered the pre-SSE earthquake swarms.
\end{abstract}

\section{Introduction}

Seismicity is strongly influenced by transient aseismic processes, such as fluid migration and episodic aseismic slip along faults. Better constraints on these aseismic processes are therefore essential for elucidating the underlying physical mechanisms of seismicity. For example, fluid migration within the Earth's crust can transiently increase pore-fluid pressure and thus reduce the effective confining pressure and shear strength of faults (e.g., Raleigh et al., 1976; Yamashita, 1998). This phenomenon often triggers earthquake swarms, which are seismic sequences without a distinguishable mainshock (e.g., Yoshida et al., 2019). Migration of epicenters of earthquake swarms has been observed in various volcanic regions, such as the Yellowstone volcanic field, USA (Waite \& Smith, 2002), and the Hida Mountains, Japan (Aoyama et al., 2002), and is thought to be indicative of hydrothermal fluid migration. Furthermore, the excessive discharge of groundwater in Matsushiro, Japan, where $10^{7} \mathrm{~m}^{3}$ of discharge was observed during the 1965-1970 earthquake swarm episodes, coincided with gradual expansion of the epicentral area (e.g., Tsuneishi \& Nakamura, 1970), providing strong evidence for a close relationship between earthquake swarms and subsurface fluid migration.

A slow slip event (SSE), which is defined by episodic aseismic slip along the plate interface in subduction zones, is often accompanied by earthquake swarms. For example, SSEs $\left(6.6 \leq M_{w} \leq 6.7\right)$ accompanied by earthquake swarms $\left(M_{w} \leq 5.3\right)$ have been geodetically observed with 2-7-years recurrence intervals in the Boso-Oki region of eastern Japan, where the Philippine Sea Plate subducts under the Okhotsk Plate (e.g., Fukuda, 2018; Fukuda et al., 2014; Ozawa et al., 2003). These earthquake swarms are interplate thrust events that are located along the downdip edges of the SSE source regions. Their seismicity rates are positively correlated in space and time with SSE slip rates, suggesting that SSE-induced stress loading is the trig- 
gering mechanism for these earthquake swarms (Fukuda, 2018; Fukuda et al., 2014). A similar space-time relationship between SSEs and earthquake swarms has been observed in the Japan (Kawasaki et al., 1995), Mexico (Liu et al., 2007), Hikurangi (Delahaye et al., 2009), Ecuador (Vallée et al., 2013), Peru (Villegas-Lanza et al., 2016), and northern Chile (Socquet et al., 2017) trenches.

Furthermore, attempts have been made to detect offshore SSEs by examining the earthquake swarm activity in subduction zones, such as the Japan and Aleutian trenches (e.g., Marsan et al., 2013; Nishikawa et al., 2019; Reverso et al., 2015). A prominent example is an interplate earthquake swarm $\left(M_{w} \sim 5\right)$ that preceded the $2011 M_{w} 9.0$ Tohoku-Oki earthquake, whose epicenters migrated at $2-5 \mathrm{~km} /$ day. Kato et al. (2012) suggested that this observed earthquake swarm activity was indicative of an SSE that preceded the Tohoku-Oki mainshock and ruptured the central part of the Japan Trench $\left(38^{\circ} \mathrm{N}-39^{\circ} \mathrm{N}\right)$ over a 1-month period. This idea was subsequently supported by an ocean-bottom pressure gauge observation (Ito et al., 2013).

The Hikurangi Trench is an oceanic trench off the North Island of New Zealand, where the Pacific Plate subducts under the Kermadec Plate (Bird, 2003). This trench is an ideal region to investigate the relationship between aseismic transients and seismicity, since various types of fault slip phenomena (small to large and slow to fast) coexist and interact in this subduction zone. The diverse behavior of SSEs along the plate interface has been recorded (e.g., Wallace \& Beavan, 2010), with short-duration ( $<1$ month), shallow ( $<15 \mathrm{~km}$ ) SSEs repeatedly occurring along the northern part of the trench (Figure 1) and long-duration (>1 year), deep SSEs occurring along the southern part (Wallace, 2020). The shallow SSEs $\left(M_{w}<7\right)$ are often accompanied by intensive earthquake swarms $\left(M_{w} \leq 5\right)$ (e.g., Delahaye et al., 2009; Wallace et al., 2012) and tectonic tremors (e.g., Todd \& Schwartz, 2016). Large earthquakes in this trench are also related to SSEs. For example, the $2016 M_{w} 7.8$ Kaikoura earthquake, which occurred at the southern end of the Hikurangi Trench (Hamling et al., 2017) and is the second-largest earthquake to be recorded in New Zealand, dynamically triggered SSEs across the entire trench (Wallace et al., 2017).

Crustal fluid also plays an important role in the subduction zone deformation processes along the Hikurangi Trench. Warren-Smith et al. (2019) inferred a fluid accumulation cycle within the subducting oceanic crust via a stress inversion that analyzed the focal mechanisms of intra-slab earthquakes. Pore-fluid pressure builds up within the oceanic crust during the inter-SSE periods and peaks just prior to the onset of SSEs. It decreases immediately following the SSE onsets. Warren-Smith et al. (2019) interpreted this to be because the enhanced permeability caused by the SSEs allows the drainage of overpressurized fluids from the subducting oceanic crust to the plate boundary and upper plate. Warren-Smith et al. (2019) also suggested that SSEs may be triggered when the pore-fluid pressure within the oceanic crust reaches a certain maximum threshold, thereby implying the potential to predict SSE onset times. Overpressurized fluids are also related to seismicity along the Hikurangi Trench. Shaddox and Schwartz (2019) found that swarm-like microseismicity within an upper-plate fracture network, located above a subducting seamount, began a few days before the end of the September-October $2014 M_{w} 6.8$ Gisborne shallow SSE and continued for nearly 2 months after the SSE. They proposed that fluid migration from the plate boundary to the fracture network occurred during the SSE period and diverted SSE-related aseismic slip along the plate boundary to multiple faults within the upper plate, which in turn triggered this delayed microseismicity.

Fluid migration, SSEs, and seismicity interact closely in the Hikurangi Trench. Therefore, the comprehensive detection of earthquake swarms along the Hikurangi Trench can contribute to elucidating the causal relationship between aseismic phenomena and seismicity. Furthermore, a detailed examination of earthquake swarm activity can be useful for detecting new transient aseismic processes, such as small SSEs that have previously escaped detection. Jacobs et al. (2016) created a catalog of earthquake clusters (nonbackground seismicity) occurring from 2002 to 2011 in the North Island of New Zealand and compared the catalog with known SSEs. However, this catalog does not distinguish between earthquake swarms and ordinary mainshock-aftershock sequences-which are the outcomes of earthquake-to-earthquake triggering and decay according to the Omori-Utsu's aftershock law (e.g., Ogata, 1988)—even though the distinction between earthquake swarms and mainshock-aftershock sequences is important for relating earthquake clusters to transient aseismic processes. This catalog also has not been examined to detect new transient 


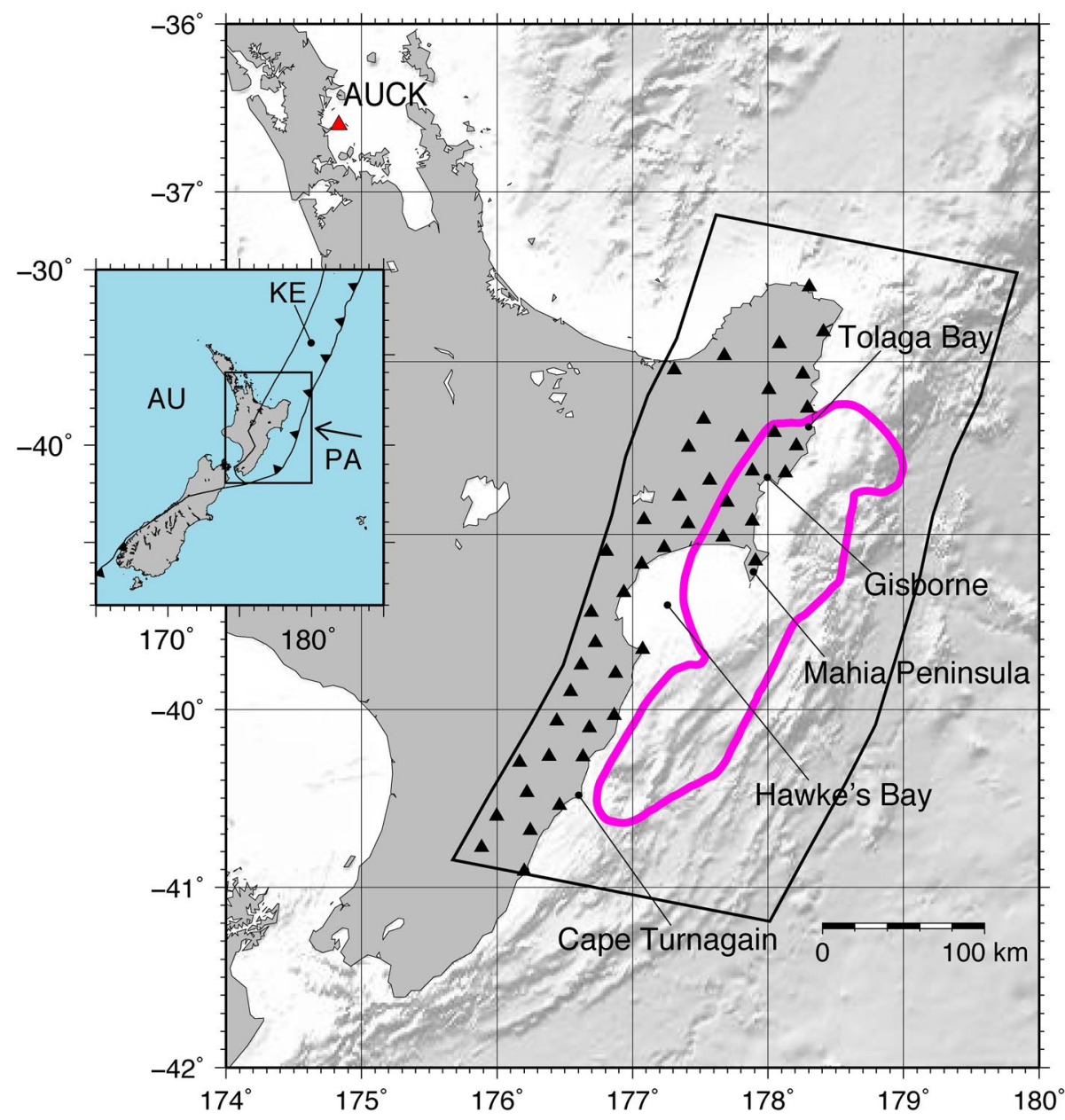

Figure 1. Our study region and shallow SSE source regions along the northern and central Hikurangi Trench. The black polygon indicates our study region. The thick magenta contour is the $50-\mathrm{mm}$ total slip contour for the 2002-2010 shallow SSEs (Wallace \& Beavan, 2010). The black triangles are the GNSS stations used in this study. The red triangle indicates station AUCK, which was fixed for the GNSS displacements. The inset map shows the tectonic setting of New Zealand; PA, KE, and AU indicate the Pacific, Kermadec, and Australian plates, respectively, with the black arrow representing PA plate motion relative to KE. GNSS, global navigation satellite system; SSE, slow slip events.

aseismic processes, such as small SSEs. Furthermore, while there has been a marked improvement in tectonic tremor catalogs along the northern and central Hikurangi Trench since 2016 (Romanet \& Ide, 2019; Todd et al., 2018; Todd \& Schwartz, 2016), a detailed comparison between the tectonic tremor catalogs and an earthquake swarm catalog has not been performed.

Here we apply the epidemic-type aftershock sequence (ETAS) model (Ogata, 1988; Zhuang et al., 2002) to seismicity $(M \geq 3.0)$ along the northern and central Hikurangi Trench. We distinguish earthquake swarms from ordinary mainshock-aftershock sequences based on the Omori-Utsu's aftershock law and create a new earthquake swarm catalog for the 1997-2015 period, which is longer than the sequence catalog by Jacobs et al. (2016). We then compare our new earthquake swarm catalog with Global Navigation Satellite System (GNSS) time series data, and existing SSE (Wallace \& Beavan, 2010; Wallace \& Eberhart-Phillips, 2013; Wallace et al., 2012, 2016) and tectonic tremor (Romanet \& Ide, 2019; Todd \& Schwartz, 2016; Todd et al., 2018) catalogs, to both elucidate the causal relationship between aseismic phenomena and seismicity and detect new transient aseismic processes. 


\section{Data and Methods}

\subsection{Study Region and Earthquake Catalog}

Figure 1 shows the location of our study region in the Hikurangi Trench. The study region comprises an $\sim 500 \mathrm{~km}$ long-trench section, that extends $200 \mathrm{~km}$ in the direction of Pacific Plate motion relative to Kermadec Plate motion (Bird, 2003). As the focus of our study is on earthquake swarms associated with shallow SSEs, we selected the location and size of our study area to encompass the source regions of the shallow SSEs off the east coast of the North Island (Wallace \& Beavan, 2010; Figure 1).

More than 15,000 $M \geq 2.0$ earthquakes that occur in New Zealand and the immediate offshore regions are located and archived in the GeoNet earthquake catalog every year (Petersen et al., 2011). The number of seismic stations used to locate earthquakes in this catalog progressively increased. In 1997, 40 short-period seismometers and no broadband seismometers were in operation in New Zealand. This increased to 125 short-period seismometers and 74 broadband seismometers by 2015 . We extracted all of the earthquakes that occurred inside the study region from January 1, 1997 to December 31, 2015 from the GeoNet earthquake catalog (Figure 2a). We did not limit our analysis to interplate earthquakes because the earthquake swarms associated with SSEs in the Hikurangi Trench do not necessarily occur along the plate interface (Jacobs et al., 2016; Shaddox \& Schwartz, 2019).

The earthquake location algorithm of the GeoNet earthquake catalog was changed in 2012 and its earthquake location procedure was fully automated. Therefore, we divided our data and analyses into pre-2012 and 2012-2015 periods. The epicentral errors are generally a few kilometers or less for onshore and nearshore earthquakes and several kilometers for offshore earthquakes. We then estimated the magnitude of completeness for the extracted earthquakes using the maximum curvature method (Wiemer \& Wyss, 2000) and a correction value of 0.2, as recommended by Woessner and Wiemer (2005). The estimated magnitude of completeness values exhibited temporal variations, with 3.0, 2.7, 2.5, and 3.1 estimated for the 19972001, 2002-2006, 2007-2011, and 2012-2015 periods, respectively. The magnitude of completeness for the 2012-2015 period was the highest, indicating that this period was least complete. This was probably due to the change in the earthquake location algorithm and procedure in 2012. Nevertheless, we used all of the $M \geq 3.0$ earthquakes that occurred inside the study region during the 1997-2015 period to detect earthquake swarms, as our earthquake swarm detection method-which detects anomalous earthquake clusters based on the ETAS model (see Section 2.2) - is proven to work, even if the earthquake catalog is slightly incomplete (Nishikawa \& Ide, 2018; Ogata, 2005). However, we cannot compare the detected number of earthquake swarm sequences between the pre-2012 and 2012-2015 periods because they are directly dependent on the magnitude of completeness. We note that the detected number of earthquake swarm sequences is underestimated during the 2012-2015 period.

\subsection{Earthquake Swarm Detection Using the ETAS Model}

We followed the earthquake swarm detection method published in Nishikawa and Ide (2018), and Nishikawa et al. (2019); their method is outlined in the following paragraphs. We detected the earthquake swarms by defining them as anomalous earthquake clusters that do not obey the Omori-Utsu aftershock law, which states that aftershock seismicity rates exhibit a power-law decay. Therefore, the ETAS model, which expresses the seismicity rate as the summation of a stationary background seismicity rate and the superposition of the Omori-Utsu derived aftershock rate, cannot describe the swarm activities. Numerous studies have shown that employing the ETAS model with a stationary background seismicity rate can describe earthquake-to-earthquake triggering well (e.g., Ogata, 1988; Zhuang et al., 2002) but cannot describe triggering by transient aseismic processes (e.g., Llenos et al., 2009).

The seismicity rate $\lambda$ at a location $(x, y)$ and time $t$ in the space-time ETAS model (Zhuang et al., 2002) is given as:

$$
\lambda(t, x, y)=\mu(x, y)+\sum_{t_{i}<t} \kappa\left(M_{i}\right) g\left(t-t_{i}\right) f\left(x-x_{i}, y-y_{i} ; M_{i}\right),
$$


(a)

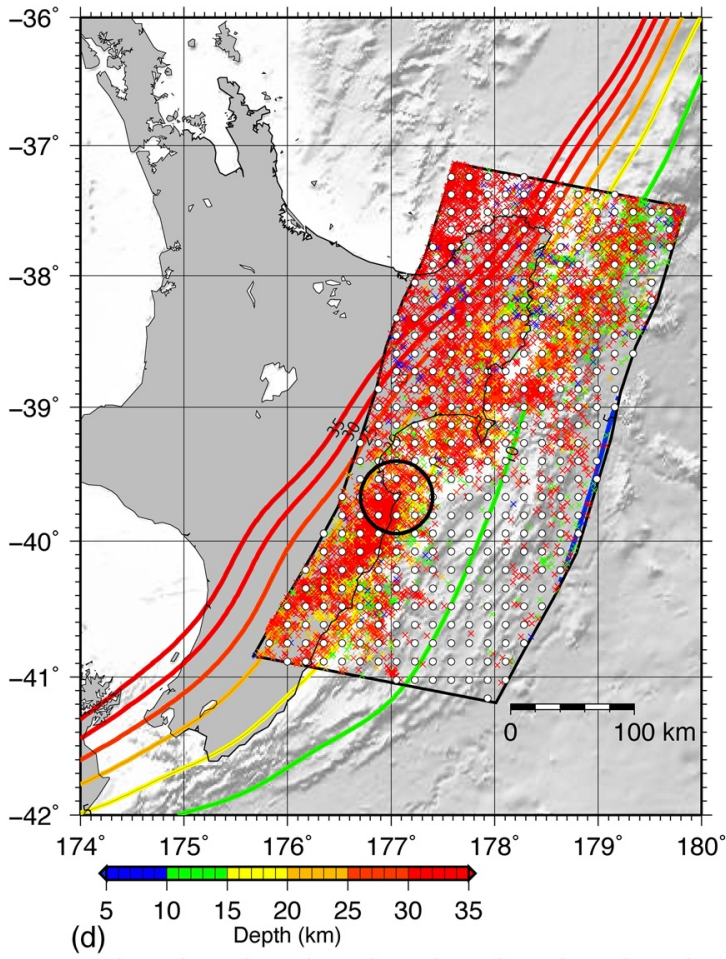

(b)

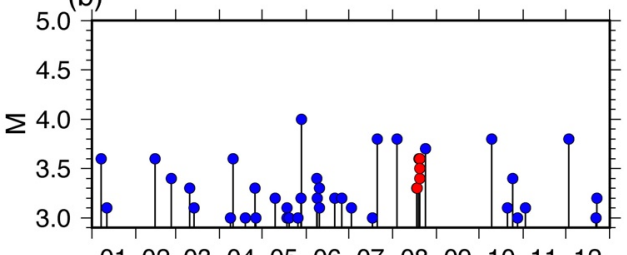

$\begin{array}{llllllllllll}01 & 02 & 03 & 04 & 05 & 06 & 07 & 08 & 09 & 10 & 11 & 12\end{array}$ (c)

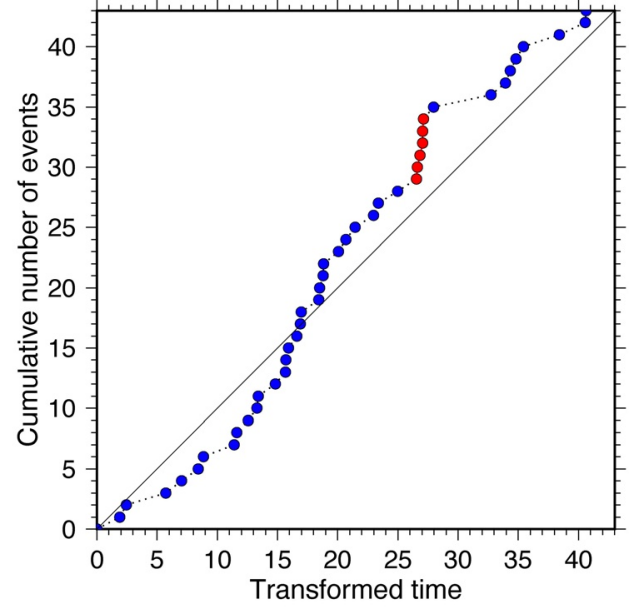

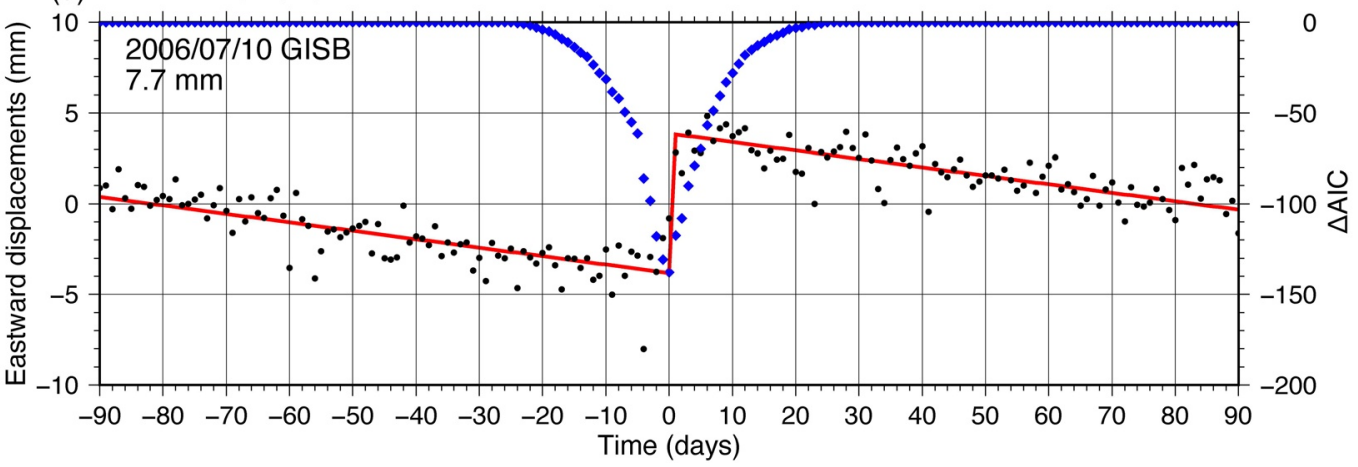

Figure 2. Earthquake swarm detection and transient GNSS displacement detection. (a) Observed seismicity in our study region. The black polygon indicates our study region. The epicenters of $M \geq 3$ earthquakes during the 1997-2015 study period (small crosses) are color-coded according to depth. The colored contours are depth contours of the subducting plate interface (5-km interval; Hayes, 2018). The large black open circle and small white solid circles represent a detection circle and the centers of the detection circles, respectively (see Section 2.2). (b) Magnitude-time diagram for the seismicity within the detection circle (large open black circle) in (a) in 2006. The red and blue circles are the detected swarm and nonswarm events, respectively. (c) Transformed time sequence for the seismicity in (b). The black line indicates a line with a gradient unity. The earthquake swarm events (red circles) yield a slope with a gradient that is much larger than unity, which indicates that the observed number of events is much larger than the predicted number of events. (d) Detection of a transient GNSS displacement. The black points are the GNSS daily coordinates for a 180-days moving time window. The red line is a fitted linear function with an offset. The blue diamonds indicate the $\Delta$ AICs (difference in Akaike's information criterion values; see Section 2.3) that are calculated for the 180-days moving time windows, whose centers correspond with the dates of the blue diamonds. GNSS, global navigation satellite system.

where $\mu(x, y)$ is the background seismicity rate, $\kappa(M)$ is the expected number of aftershocks for an earthquake of magnitude $M, g(t)$ is the probability density of the aftershock lag times, and $f(x, y ; M)$ is the probability density of aftershock locations. The second term in Equation 1 is the aftershock rate of preceding earthquakes of magnitude $M_{i}$ located at $x_{i}$ and $y_{i}$, and time $t_{i}$, where $M_{i} \geq M_{c}$ and $t_{i}<t . M_{c}$ is the magnitude 
of completeness (minimum magnitude), which has a value of 3.0 in our analysis (see Section 2.1). $\mu(x, y)$ is defined as:

$$
\mu(x, y)=v u(x, y)
$$

where $v$ is a positive-valued parameter close to unity and $u(x, y)$ is the spatial intensity function. The variables in the second term in Equation $1(\kappa(M), g(t)$, and $f(x, y ; M))$ are defined as:

$$
\begin{gathered}
\kappa(M)=A e^{\alpha\left(M-M_{c}\right)}, \\
g(t)=\frac{p-1}{c}\left(1+\frac{t}{c}\right)^{-p},
\end{gathered}
$$

and

$$
f(x, y ; M)=\frac{q-1}{\pi D^{2} e^{\gamma\left(M-M_{c}\right)}}\left(1+\frac{x^{2}+y^{2}}{D^{2} e^{\gamma\left(M-M_{c}\right)}}\right)^{-q},
$$

where the seven parameters $A, c, \alpha, p, D, q$, and $\gamma$ control the aftershock rate of the preceding earthquakes. We used the $M \geq 3.0$ earthquakes that occurred inside the study region during the 1997-2015 study period (Figure 2a) to estimate the eight ETAS parameters $v, A, c, \alpha, p, D, q$, and $\gamma$ via the maximum likelihood method. We divided the pre-2012 period (see Section 2.1) into three 5-years sub-periods (1997-2001, 20022006, and 2007-2011) for the parameter estimation, based on the calculation time needed to estimate the ETAS parameters. See Zhuang et al. (2002) for details of the maximum likelihood estimation and calculation of the spatial intensity function $u(x, y)$. When estimating the ETAS parameters, we also used the seismicity in the year preceding each of the analyzed periods (1997-2001, 2002-2006, 2007-2011, and 2012-2015) in order to calculate the seismicity rate increase during the analyzed period caused by the triggering effect of the earthquakes in the preceding year. This procedure is especially important when a great earthquake $(M \geq 7)$ occurred in the preceding year because a $M \geq 7$ earthquake can be followed by numerous $M \geq 3$ aftershocks over a long time. Without this procedure, the numerous aftershocks bias the ETAS parameters for the analyzed period.

In the usual procedure of the ETAS analysis, one estimates the ETAS parameters using data during a normal period (e.g., nonswarm period) and then applies the parameters to an anomalous period (e.g., swarm period; Ogata, 2005). In this procedure, we need to know the onset and end time of the earthquake swarm activities in advance. However, in our earthquake swarm detection, we do not know the onset and end time in advance. Therefore, the usual procedure of the ETAS analysis is not applicable to our study. Furthermore, because earthquake swarms occur very frequently in the Hikurangi Trench, it is almost impossible to estimate the ETAS parameters for nonswarm and swarm periods separately. Considering these facts, we estimated the ETAS parameters using a given period and applied the parameters to the same period. This approach is the same as the approach taken by Ogata (1988) to detect seismic quiescence.

We then calculated the number of events predicted by the space-time ETAS model in circles of $30 \mathrm{~km}$ radius (e.g., the large black open circle in Figure 2a) throughout the study region using the estimated ETAS parameters. The diameter of each circle $(60 \mathrm{~km})$ is comparable to the spatial scale of the epicentral distribution of the earthquake swarms associated with the June-July $2011 M_{w} 6.8$ SSE, which occurred off Cape Turnagain in the Hikurangi Trench (Wallace et al., 2012). The centers of the circles were distributed at $15 \mathrm{~km}$ intervals (small white solid circles in Figure 2a). We call these circles "detection circles." The number of events predicted by the ETAS model $\Lambda(t)$ in a detection circle $S$ from time 0 to $t$ can be calculated as:

$$
\Lambda(t)=\int_{0}^{t} \iint_{S} \lambda\left(t^{\prime}, x, y\right) d x d y d t^{\prime}
$$


We executed this integration numerically, and then transformed the occurrence time $t_{i}$ of event $i$ in detection circle $S$ into a transformed time $\tau_{i} \equiv \Lambda\left(t_{i}\right)$. The transformed time $\tau_{i}$ will follow a standard Poisson process if the seismicity in the detection circle is well predicted by the ETAS model, such that a plot of the cumulative number of observed events against the transformed time (i.e., the number of events predicted by the ETAS model) will be linear with a slope gradient of unity (Ogata, 1988). Slopes greater than unity mean that the observed seismicity rate is greater than the ETAS model prediction (Figures $2 \mathrm{~b}$ and $2 \mathrm{c}$ ).

The number of events expected by the ETAS model between two successive events (event $i$ and $i+1)$ in the detection circle $S$ is:

$$
\tau_{i+1}-\tau_{i}=\int_{t_{i}}^{t_{i+1}} \iint_{S} \lambda(t, x, y) d x d y d t
$$

and the standard deviation of the number of events between $\tau_{i}$ and $\tau_{i+1}$ is:

$$
\sigma=\sqrt{\tau_{i+1}-\tau_{i}}
$$

We classified a seismic sequence as a "potential earthquake swarm" when the condition $\tau_{i+1}-\tau_{i}+1.5 \sigma<1$ was true for four or more successive events. This meant that the predicted number of events between two successive events $\tau_{i+1}-\tau_{i}$ (Equation 7) in each detection circle should not exceed unity-even when considering an additional $1.5 \sigma$ factor (Equation 8 ) - for at least four successive events. We could therefore detect seismic sequences that possessed at least four times the seismicity rate predicted by the ETAS model, and require a swarm sequence to possess at least five events using this criterion (Figures $2 \mathrm{~b}$ and $2 \mathrm{c}$ ). The probability that five events obeying the ETAS model possess such a high seismicity rate is $2.39 \times 10^{-3}$, which is sufficiently low to suppress false positive detections. Nishikawa and Ide (2018) confirmed that the above criterion could detect earthquake swarm sequences triggered by SSEs in the Boso-Oki region of eastern Japan. They found that stricter criteria resulted in earthquake swarms triggered by the SSEs going undetected. After applying the above detection criterion to seismicity in all detection circles, we grouped any potential earthquake swarms with common events into a single cluster. We defined these clusters as earthquake swarms.

Nishikawa et al. (2019) calculated the probability of the first event of each swarm sequence being a background event using the ETAS model. They classified earthquake swarm sequences whose first event was a background event as "background swarms" and those whose first event was an aftershock (i.e., the probability of being a background event was less than 50\%) as "aftershock swarms." The probability $P_{b}$ that an event at $x_{i}$ and $y_{i}$, and time $t_{i}$ being a background event is given by:

$$
P_{b}=\frac{\mu\left(x_{i}, y_{i}\right)}{\lambda\left(t_{i}, x_{i}, y_{i}\right)} .
$$

Nishikawa et al. (2019) argued that background swarms and aftershock swarms are potentially triggered by spontaneous SSEs and the afterslip of preceding large earthquakes, respectively. Following their classification, 41 (33\%) of the 124 earthquake swarm sequences detected in this study were classified as aftershock swarms. However, we found that their classification criterion, which depends on the first event of each earthquake swarm sequence, often resulted in an incorrect classification. For example, if an earthquake swarm has small foreshocks whose seismicity rate does not satisfy the $\tau_{i+1}-\tau_{i}+1.5 \sigma<1$ requirement, then their classification criterion classifies the earthquake swarm sequence as an aftershock swarm because the first event of the earthquake swarm sequence is regarded as an aftershock of the small foreshocks. We found that only five of the 41 aftershock swarm sequences are intensive aftershocks of large earthquakes $(M \geq 6.0)$. There were only two large $(M \geq 6.0)$ earthquakes that were followed by intensive aftershocks during the 1997-2015 period in our study region ( $M$ 6.7 and $M$ 6.2 earthquakes in December 2007 and January 2014, respectively). Considering these facts, we disregarded the classification between the background swarms and aftershock swarms. Instead, we removed the five seismic sequences whose first event was an aftershock of either the December $2007 M 6.7$ or January $2014 M 6.2$ earthquakes—that is, the probability 
that the first event had been triggered by either large earthquake was higher than the probability of having been triggered by the other precedent earthquakes-from detected earthquake swarms. The probability $P_{i, j}$ that the $j$ th event is an aftershock of the $i$ th event is given by Zhuang et al. (2002):

$$
P_{i, j}=\frac{\kappa\left(M_{i}\right) g\left(t_{j}-t_{i}\right) f\left(x_{j}-x_{i}, y_{j}-y_{i} ; M_{i}\right)}{\lambda\left(x_{j}, y_{j}\right)} .
$$

\subsection{Detection of Transient Eastward Displacements in the GNSS Time-Series Data}

We used the GNSS time-series data from a continuous GNSS network, which is operated and maintained by GeoNet, to detect the crustal deformation that is potentially due to shallow SSEs accompanied by earthquake swarms. The daily time-series solutions are available at https://www.geonet.org.nz/data/types/geodetic; please see the website for the details of the analysis strategy for the daily time-series solutions. We selected 46 stations (which were progressively installed from 2002) along the east coast of the North Island (Figure 1) and used the north-south and east-west daily time-series data from June 28, 2002 to March 30, 2016 in our analysis. We removed the offsets due to equipment changes from the daily time series. The offsets were estimated from the differences between the 10-days averages of the daily coordinates before and after the equipment changes. In the subsequent analysis, we fixed station AUCK, which is far from the Hikurangi Trench (Figure 1); that is, we subtracted the daily coordinates at station AUCK from those at the other stations. The distance between station AUCK and the closest point in the study area is $\sim 250 \mathrm{~km}$.

We estimated the daily displacements (north-south and east-west components) and detected transient crustal movements via the method of Nishimura et al. (2013) and Nishimura (2014). This method has been applied to detect small displacements due to short-term SSEs in the Nankai Trough and Ryukyu Trench in southwest Japan (Nishimura, 2014; Nishimura et al., 2013). Here we describe their method but direct the reader to Nishimura et al. (2013) and Nishimura (2014) for full details. We first fitted a linear function with an offset in the center of a 180-days moving time window (Figure $2 \mathrm{~d}$ ) to the daily coordinates at each station using a least-squares method. We then shifted the time window in daily increments and regarded these estimated offsets as the daily displacement values.

The signals associated with the shallow SSEs that occurred inside the study region are evident especially in the east-west component, showing an eastward (i.e., positive) displacement (Figure 2d; Todd \& Schwartz, 2016). We fitted linear functions with and without an offset in the center of the 180-days moving time window and compared them based on Akaike's information criterion (AIC) (Akaike, 1974), to identify any significant transient eastward displacements that may potentially be due to shallow SSEs. We assumed that each observed daily coordinate value was independent and that the observational errors obeyed a normal distribution. The AIC is defined as:

$$
\mathrm{AIC}=n \ln (2 \pi)+n \ln \left(\frac{\sum_{i=1}^{n}\left(O_{i}-C_{i}\right)^{2}}{n}\right)+n+2 k,
$$

where $n$ and $k$ are the number of observed data and model parameters, respectively, and $O_{i}$ and $C_{i}$ are the observed and calculated values for $i$ th data, respectively. $k$ is set to 3 and 2 for linear functions with and without an offset, respectively. Figure $2 d$ shows an example of the difference in the AICs between linear functions with and without an offset for each day. Hereafter, we call this difference " $\Delta$ AIC," Negative $\Delta$ AIC values indicate that a linear function with an offset provides a better fit to the GNSS time series than a linear function without an offset. We assigned zero values to $\Delta$ AIC in Figure $2 d$ when either the estimated offset was negative (i.e., a westward displacement, which is the opposite direction of the expected displacements due to shallow SSEs) or a calculated $\triangle$ AIC value was positive. We considered a positive offset to be significant when $\Delta$ AIC was less than -2 . We retained the local minima of the $\Delta$ AIC values, with each minimum $\Delta \mathrm{AIC}$ value being the lowest over a period \pm 14 days from the day possessing the minimum. Finally, we regarded each day possessing a local minimum $\Delta$ AIC value to represent a day when significant transient eastward displacements that were potentially due to shallow SSEs occurred. 


\subsection{Formation of Earthquake Swarm-Transient GNSS Displacement Pairs}

We compared the detected earthquake swarms with significant transient eastward displacements to find potential SSEs that were accompanied by earthquake swarms. We formed pairs consisting of an earthquake swarm sequence and the transient eastward displacement that was recorded at the closest station to the centroid of the earthquake swarm sequence and at the closest time to the center of the occurrence period of the earthquake swarm sequence. We required the center of the occurrence period of each earthquake swarm sequence to be within 90 days of a transient displacement. Note that a transient displacement can be paired with multiple earthquake swarm sequences. We focused on the earthquake swarms located along the east coast of the North Island, and disregarded the earthquake swarm sequences whose centroids were far from the GNSS stations (i.e., more than $60 \mathrm{~km}$ away from the closest GNSS station). In addition, we checked the influence of the epicentral uncertainty of the earthquake swarms $(\sim 3 \mathrm{~km})$ on the formation of the earthquake swarms-transient GNSS displacement pairs. We confirmed the epicentral uncertainty does not affect our results (see supporting information S1).

We then roughly estimated the moment magnitudes and source locations of the possible SSEs that caused significant transient eastward displacements paired with earthquake swarms. We did this by estimating their rectangular fault models via a grid search. Although we detected transient eastward GNSS displacements regardless of whether they were accompanied by earthquake swarms or not, we modeled only possible new SSEs accompanied by earthquake swarms when we had daily displacement values at a sufficient number of stations (4 stations or more) within $100 \mathrm{~km}$ from the centroid of the paired earthquake swarm sequences. We also required that at least two of the daily displacement values were significant $(\Delta \mathrm{AIC}<-2)$. Even when we did not have daily displacement values at a sufficient number of stations, we regarded the transient GNSS displacements paired with earthquake swarms as transient GNSS displacements possibly caused by new SSEs and discussed them in Section 3.3. We did not model transient eastward GNSS displacements without paired earthquake swarms because the main objective of this study is to detect earthquake swarms along the Hikurangi Trench and elucidate the causal relationship between earthquake swarms and transient aseismic processes. The comprehensive detection of new SSEs is beyond the scope of this study.

In the grid search, we fixed our fault models onto the Pacific Plate (Hayes, 2018), such that the depth, strike, and dip of a rectangular fault were only dependent on the horizontal location. We assumed that the slip direction was parallel to the plate convergence direction $\left(\sim \mathrm{N} 80^{\circ} \mathrm{W}\right.$; Bird, 2003$)$. The aspect ratio of the rectangular fault models was set to 1 for the sake of simplicity. The longitude, latitude, width, and slip amount were free parameters in the fault models. We changed the horizontal location (i.e., longitude and latitude), width, and slip amount of each fault model at $0.2^{\circ}, 10-\mathrm{km}$, and $1-\mathrm{cm}$ intervals, respectively. Earthquake swarms in the Hikurangi Trench are often located at the periphery of SSE source regions (Wallace et al., 2012). Considering this fact, we searched the horizontal locations of SSE fault models across sufficiently large areas ( $2^{\circ}$ in latitude and longitude) encompassing the centroids of the paired earthquake swarm sequences. We calculated the surface displacements due to a rectangular fault buried in an elastic half-space (Okada, 1985) with a rigidity of $30 \mathrm{GPa}$ and Poisson ratio of 0.25 , and selected the fault model that minimized the root mean square (RMS) error.

\section{Results}

\subsection{Earthquake Swarms in the Hikurangi Trench}

Table 1 shows the maximum likelihood estimates (MLEs) of the 8 ETAS parameters for the four periods (1997-2001, 2002-2006, 2007-2011, and 2012-2015). $\boldsymbol{A}$ and $\boldsymbol{\alpha}$ are the most important parameters for the earthquake swarm detection because they control the expected number of aftershocks (Equation 3 ). The average $\boldsymbol{A}$ and $\boldsymbol{\alpha}$ values for the four periods are 0.320 and 1.50, respectively, which indicates that the expected number of $M \geq 3.0$ aftershocks for $M 3, M 4$, and $M$ five earthquakes in the Hikurangi Trench are 0.3, 1.4, and 6.4 , respectively.

We detected 119 earthquake swarm sequences from the observed seismicity along the Hikurangi Trench during the 1997-2015 study period using the earthquake swarm detection method with the MLEs of the ETAS parameters listed in Table 1. This new earthquake swarm catalog is provided in the supporting 
Table 1

Maximum Likelihood Estimates of the ETAS Parameters

\begin{tabular}{cccccccccc}
\hline Time period & & $v$ & $A$ & $c$ & $\alpha$ & $p$ & $D$ & $q$ & $\gamma$ \\
\hline \multirow{3}{*}{ Pre-2012 } & $1997-2001$ & 1.03 & 0.285 & $4.92 \times 10^{-3}$ & 1.07 & 1.06 & $9.73 \times 10^{-4}$ & 1.61 & 0.288 \\
& $2002-2006$ & 1.03 & 0.337 & $5.82 \times 10^{-3}$ & 1.40 & 1.04 & $5.09 \times 10^{-4}$ & 1.74 & 0.702 \\
& $2007-2011$ & 1.04 & 0.314 & $7.79 \times 10^{-3}$ & 1.64 & 1.06 & $5.98 \times 10^{-4}$ & 2.13 & 0.915 \\
$2012-2015$ & & 1.06 & 0.345 & $3.99 \times 10^{-3}$ & 1.90 & 1.03 & $0.12 \times 10^{-4}$ & 1.43 & 0.928 \\
\hline
\end{tabular}

Abbreviation: ETAS, epidemic-type aftershock-sequence.

information (Data Set S1). Figures 3a and 3b show the distribution of total events and detected earthquake swarm events in each detection circle during the 1997-2015 study period. We detected many earthquake swarm events, especially in the detection circles along the east coast of the North Island (Figure $3 \mathrm{~b}$ ). 50 or more swarm events were detected in the detection circles near the coast, at $\sim 38.2^{\circ} \mathrm{S}, 39.0^{\circ} \mathrm{S}$, and $40.6^{\circ} \mathrm{S}$. Fewer earthquake swarm events were detected within the inland detection circles (i.e., less than 20 events in a given detection circle) (Figure 3b), although the number of total events (i.e., the total number of swarm events and nonswarm events) is relatively high in these inland detection circles (reddish color in Figure 3a). This suggests that although inland seismicity occurs at a high rate, it does not show the anomalous temporal clustering which we set as a requirement for earthquake swarm classification (see Section 2.2). Examples of the detected earthquake swarm sequences are shown in Figures 3c-3e. These earthquake swarm sequences lack a clear mainshock, which is a typical feature of earthquake swarms. The three earthquake swarm sequences in Figure 3e occurred close in space and time to the August-September $2006 M_{w} 6.9$ south Hawke's Bay SSE, which we will discuss in more detail in section 3.3.

We present both the spatiotemporal distribution and focal mechanisms of detected earthquake swarm events in Figure 4. The 27 centroid moment tensor solutions were provided by GeoNet. Eight of the 27 focal mechanisms were reverse faults, with the rake angles $\lambda$ of either nodal plane lying in the range $45^{\circ} \leq \lambda \leq 135^{\circ}$. We note that there are only 2 low-angle reverse fault mechanisms whose strikes are compatible with the subduction plate interface (i.e., $200 \pm 45^{\circ}$ ), consistent with previous studies that highlighted the scarcity of interplate earthquakes and abundance of intraslab earthquakes along the Hikurangi Trench
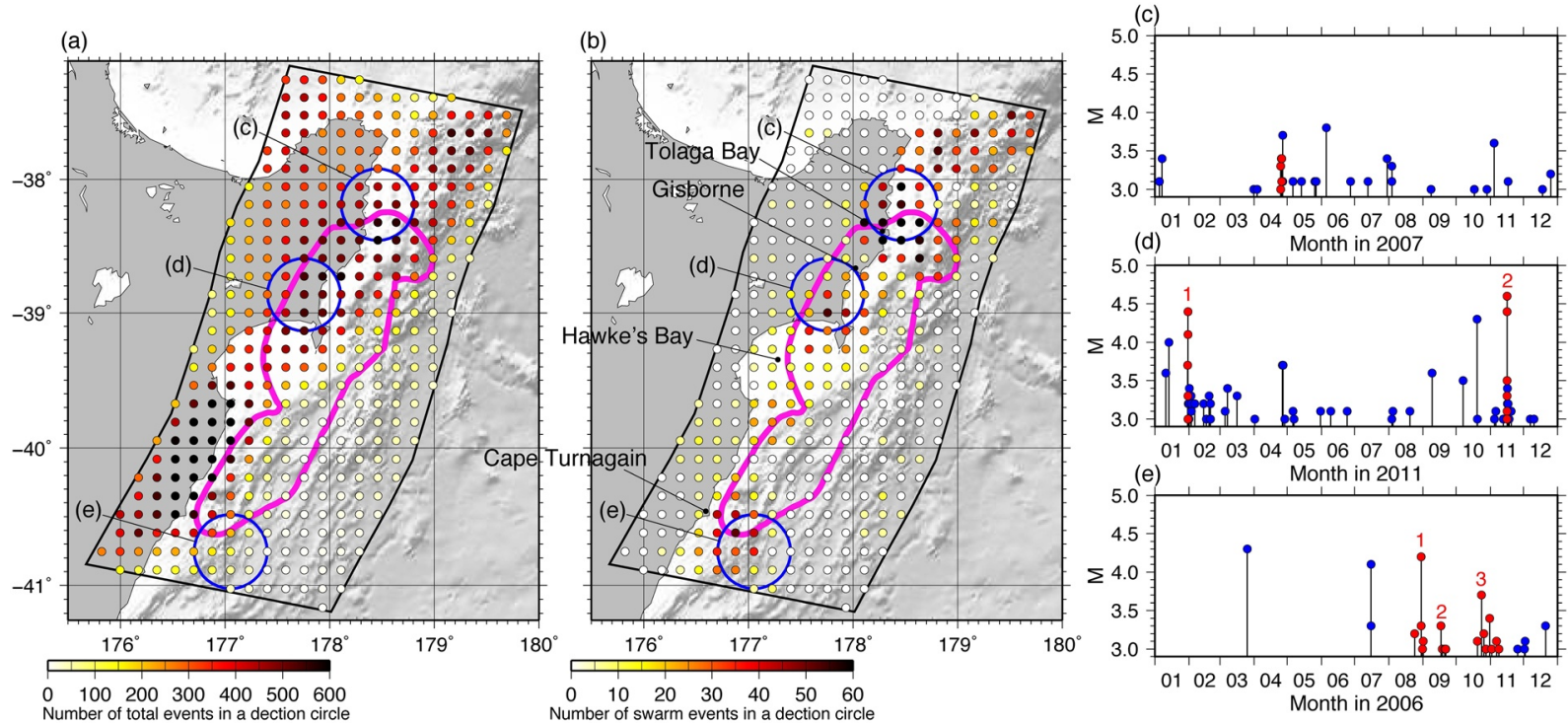

Figure 3. Detected earthquake swarms in the Hikurangi Trench during the 1997-2015 period. (a) Distribution of total events during the 1997-2015 study period. Each colored circle represents the number of total events within its associated detection circle. The blue open circles are example detection circles. The thick magenta contour is the 50-mm total slip contour for the 2002-2010 shallow SSEs (Wallace \& Beavan, 2010). (b) Distribution of detected swarm events during the 1997-2015 study period within the detection circles. (c-e) Magnitude-time diagrams for the seismicity within the example detection circles in (a). The red and blue circles are swarm and nonswarm events, respectively. SSE, slow slip events. 
(a)
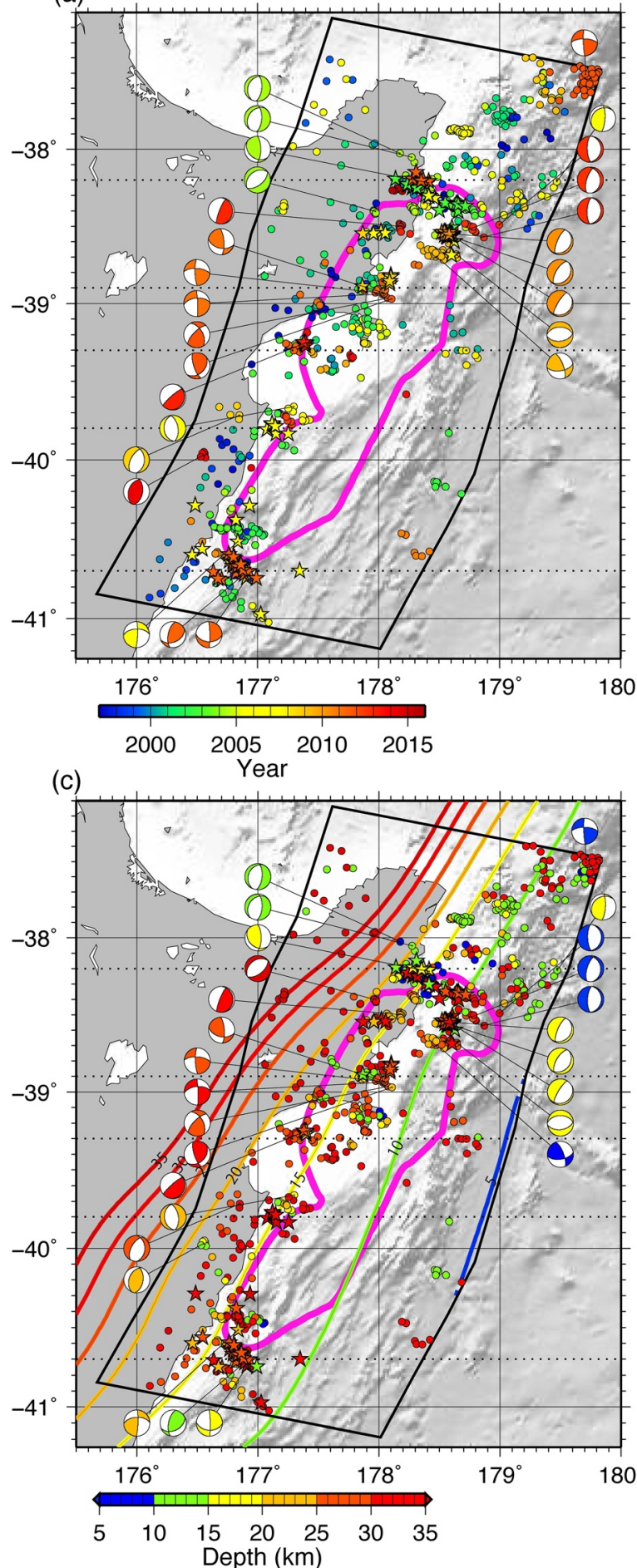

(b)

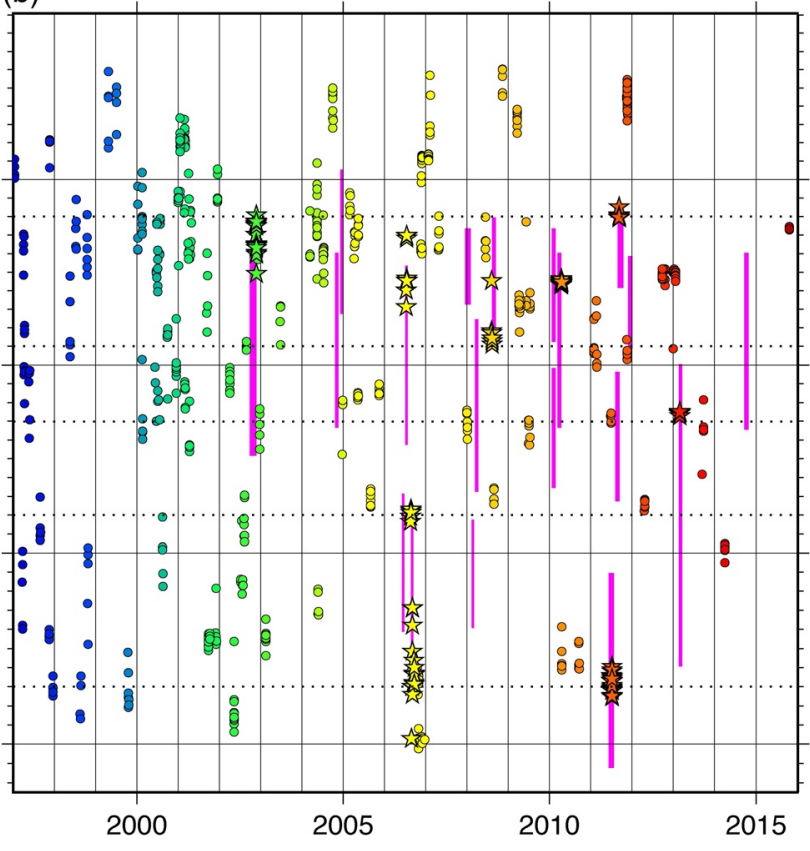

(d)

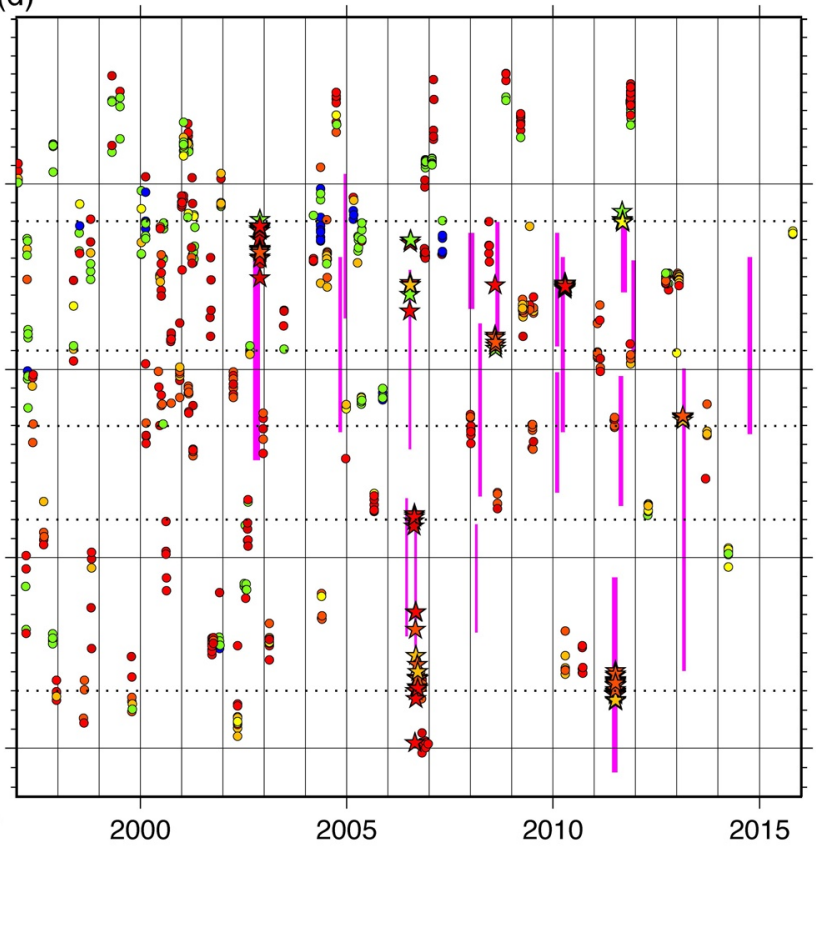

Figure 4. Spatiotemporal distribution of detected earthquake swarms. (a) and (c) Epicentral distribution of detected earthquake swarms. The small circles are the detected swarms, which are colored according to the (a) occurrence time and (c) depth. The colored stars indicate the earthquake swarms that are associated with the SSEs in existing catalogs. The focal mechanisms are also colored according to the occurrence time and centroid depth in (a) and (c), respectively. The black lines that extend from the focal mechanisms indicate the centroid locations. The thick magenta contour is the 50-mm total slip contour for the 2002-2010 shallow SSEs (Wallace \& Beavan, 2010). The colored contours in (c) are depth contours of the subducting plate interface (5-km interval). (b and d) Latitude-time diagrams for the earthquake swarms in (a and c), respectively. The magenta lines denote the spatiotemporal extents of the SSEs detected by previous studies (Wallace \& Beavan, 2010; Wallace \& Eberhart-Phillips, 2013; Wallace et al., 2012, 2016). SSE, slow slip events. 
(e.g., Warren-Smith et al., 2019; Yarce et al., 2019). The other 19 focal mechanisms were either normal or strike-slip fault mechanisms, which indicated that most of the detected earthquake swarms were intraplate events. Figure $4 \mathrm{c}$ shows the focal depths of the detected earthquake swarms. The focal depths and mechanisms indicate that there are likely both intraslab and upper-plate swarm events in the study region. The centroid depth for 12 of the 19 normal or strike-slip focal mechanisms was deeper than the plate interface, and the remaining seven events were shallower than the plate interface.

We extracted the earthquake swarms that occurred close to the SSEs detected by previous studies (Wallace \& Beavan, 2010; Wallace \& Eberhart-Phillips, 2013; Wallace et al., 2012, 2016) in both space and time from our earthquake swarm catalog. Here we selected 14 earthquake swarm sequences that occurred within 14 days of the SSE occurrence periods and were located either within or on the periphery of the SSE source regions. Eight of the 19 SSEs were associated with earthquake swarms. The earthquake swarms associated with SSEs are indicated by the colored stars in Figure 4 and are distributed at $\sim 38.2^{\circ} \mathrm{S}, 38.9^{\circ} \mathrm{S}, 39.3^{\circ} \mathrm{S}, 39.8^{\circ} \mathrm{S}$, and $40.7^{\circ} \mathrm{S}$ along the east coast of the North Island. These regions are characterized by recurrent earthquake swarms (as is shown in Figures $4 \mathrm{~b}$ and $4 \mathrm{~d}$ ), implying the existence of characteristic intraplate structures that facilitate the recurrence of earthquake swarms, which we will discuss in more detail in Sections 3.3 and 4.1. Furthermore, as there are many earthquake swarm sequences whose epicenters are close to other swarms associated with known SSEs in these regions, it may be that some earthquake swarms are indicative of small SSEs that have previously escaped detection. This possibility is further explored in Section 3.3.

\subsection{Characteristics of the Detected Earthquake Swarms}

We summarized the characteristics of the detected earthquake swarms in Figure 5. The detected earthquake swarm sequences contain events ranging from 5 to 18, with an average of 6.8 events and a standard deviation of 2.5 events per swarm sequence. The earthquake swarm with the largest number of events (18 events) occurred near Tolaga Bay between May 9 and 12, 2004. This earthquake swarm is not associated with the SSEs detected by previous studies (e.g., Wallace \& Beavan, 2010). The maximum magnitude of a given earthquake swarm sequence varies over the M 3.2-5.5 range, with an average magnitude of 3.9 and a standard deviation of 0.5 . The magnitude difference between the largest and second-largest earthquakes in a swarm sequence varies from 0 to 1.7 , with an average of 0.3 and a standard deviation of 0.3 . This average magnitude difference (0.3) is quite small, indicating that the detected earthquake swarms lack a clear mainshock, which is a typical feature of earthquake swarms. The duration of a given earthquake swarm sequence ranges from less than $1 \mathrm{~h}$ to 66.9 days, with an average of 3.9 days and a standard deviation of 7.4 days. We note that the earthquake swarm with the longest duration (66.9 days) is an outlier. This earthquake swarm started $\sim 1$ month after the August-September $2006 M_{w} 6.9$ south Hawke's Bay SSE, and lasted from October 15, 2006 to December 21, 2006. A part of this earthquake swarm sequence is shown in Figure 3e (Cluster 3).

We compared the earthquake size-frequency distribution between the earthquake swarm and nonswarm events in Figure 5e. The $b$-values of the Gutenberg-Richter relationship (Gutenberg \& Richter, 1944) were calculated via the maximum likelihood method (Aki, 1965). The estimated $b$-values for the swarm $(1.05 \pm 0.04)$ and nonswarm $(1.10 \pm 0.01)$ events are similar, although the $b$-value for the swarm events is slightly smaller than that for the nonswarm events. This contrasts a result from a global earthquake swarm catalog (Holtkamp \& Brudzinski, 2011), which suggests that the $b$-value for earthquake swarms in circum-Pacific subduction zones is higher than that for nonswarm events.

Furthermore, the earthquake size-frequency distribution for nonswarm events exhibited a deviation from the Gutenberg-Richter relationship for $M 4.1+$ events, whereas such a deviation was not evident for the swarm events (Figure 5e). This deviation suggests that the nonswarm events in the Hikurangi Trench are deficient in larger magnitude earthquakes compared with the expectation from the Gutenberg-Richter relationship. Note that the three earthquakes larger than $M 5.5$ are not the cause of the observed deviation from the Gutenberg-Richter relationship for the nonswarm events. Even if we exclude the three earthquakes larger than $M 5.5$ (i.e., $M$ 6.7, 6.2, and 5.7) from the earthquake catalog, the estimated $b$-value $(1.10 \pm 0.01)$ does not significantly differ from the value estimated using all the events ( $M 3.0$ or larger; $1.10 \pm 0.01$ ). We noticed that the earthquake magnitude-frequency distribution for the nonswarm events in Figure 5e has a change of its slope around $M 4.0$. The $b$-value estimated using $M 4.0$ or larger events is $1.35 \pm 0.05$, which is 
(a)

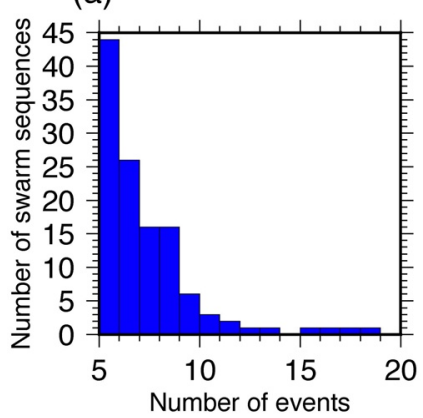

(e) (b)

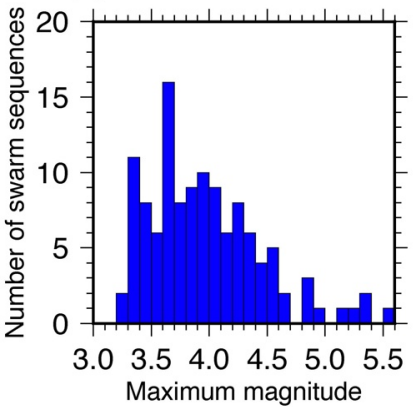

(c)

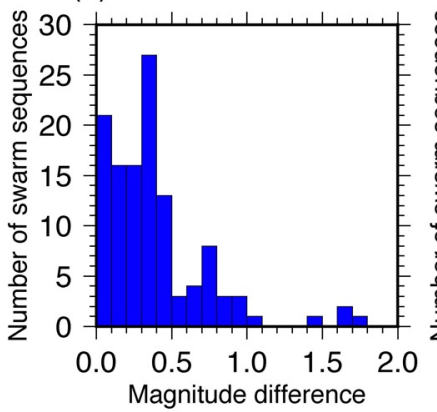

(d)

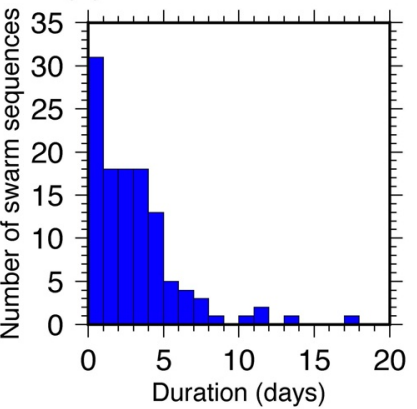

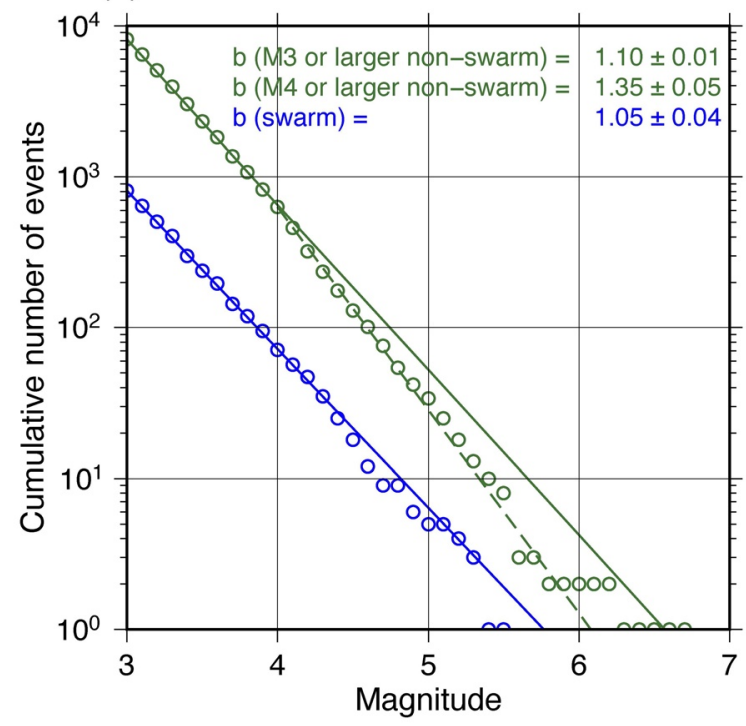

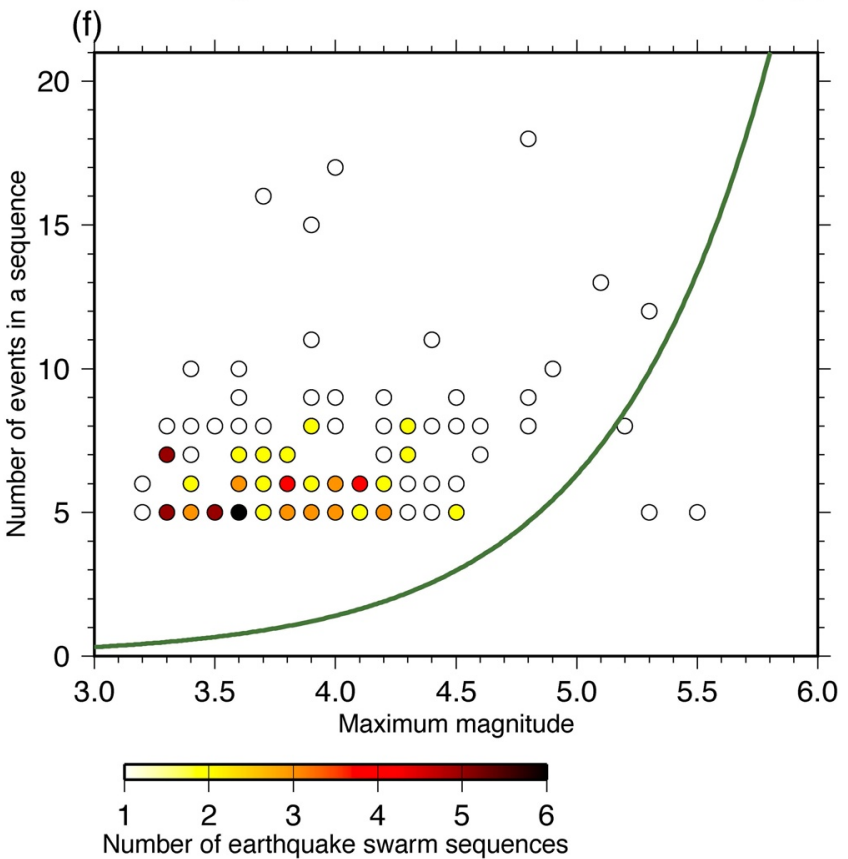

Figure 5. Characteristics of the detected earthquake swarms. (a-d) Histograms of the (a) number of events in, (b) maximum magnitude of, (c) magnitude difference between the largest and second-largest earthquakes of, and (d) duration of a given earthquake swarm sequence. (e) Earthquake size-frequency distribution for the earthquake swarm (blue open circles) and nonswarm (green open circles) events. The blue and green lines show the estimated $b$-values for the $M 3$ or larger swarm $(b=1.10)$ and nonswarm $(b=1.05)$ events, respectively. The green dashed line shows the estimated $b$-values for the $M$ four or larger nonswarm events $(b=1.35)$. (f) Relationship between the maximum magnitude and number of events in a swarm sequence. The circles are color-coded according to the number of earthquake swarm sequences with the same number of events and maximum magnitude. The green curve indicates the number of aftershocks predicted by the ETAS model using the parameters averaged over the four periods. ETAS, epidemic-type aftershock-sequence.

significantly larger than the value estimated using all the events ( $M 3.0$ or larger; $1.10 \pm 0.01)$. This change of the slope seems to cause the observed deviation from the Gutenberg-Richter relationship.

It is worth noting that $M_{w}>5.5$ SSEs occur much more frequently than $M>5.5$ ordinary earthquakes in our study region. Only $3 M>5.5$ ordinary earthquakes occurred in our study region from 1997 through 2015 (Figure 5e), whereas previous studies (Wallace \& Beavan, 2010; Wallace \& Eberhart-Phillips, 2013; Wallace et al., 2012, 2016) detected $19 M_{w} \geq 6.2$ SSEs from 2002 through 2015. Furthermore, there seem to be many smaller SSEs that have previously escaped detection (see Section 3.3). The deficiency of larger earthquakes for nonswarm events in our study region (Figure 5e) might be compensated by the frequent occurrence of SSEs with similar magnitude.

We then checked whether the detected earthquake swarms were well distinguished from ordinary mainshock-aftershock sequences based on the method proposed by Vidale and Shearer (2006). We compared the number of events in an earthquake swarm sequence to the maximum magnitude of a swarm sequence in Figure 5f. We also showed the number of aftershocks predicted by the ETAS model using the average 
parameters for the four periods (1997-2001, 2002-2006, 2007-2011, and 2012-2015; the green curve). We found no clear correlation between the number of events in a given earthquake swarm sequence and the maximum magnitude in the sequence, whereas the correlation is clear in the ETAS model prediction. Furthermore, most of the earthquake swarms have a larger number of events than those predicted by the ETAS model. These observations indicate that the detected earthquake swarm sequences cannot be explained as the aftershocks of the earthquake with the maximum magnitude in the sequence.

\subsection{Comparison Between Earthquake Swarms, Transient GNSS Displacements, and SSEs}

We then compared our earthquake swarm catalog with the significant transient eastward GNSS displacements (see Section 2.3). We detected 729 transient displacements from the east-west component of the GNSS daily time series at 45 stations along the east coast of the North Island (Figure 1). These transients include displacements due to identical SSEs. We compared the east-west GNSS daily time series at four stations (PUKE, GISB, PORA, and AKTO) to nearby earthquake swarms in Figure 6. We also compared the east-west GNSS daily time series at two stations (LEYL and CKID) to nearby earthquake swarms in Figure S1.

Shallow SSE signals were evident at the four stations (PUKE, GISB, PORA, and AKTO; see Figure 6). Stations PUKE, GISB, PORA, and AKTO recorded 28, 30, 23, and 18 significant transient eastward GNSS displacements from June 28, 2002 to December 31, 2015, respectively. We detected 38 earthquake swarm sequences in the proximity of these four stations (i.e., within the regions indicated by the dashed lines in Figure 6) during the period when the nearby stations were in operation. Twelve of the 38 earthquake swarm sequences were associated with the SSEs detected by previous studies (Wallace \& Beavan, 2010; Wallace \& Eberhart-Phillips, 2013; Wallace et al., 2012, 2016). Besides, 8 of the 38 earthquake swarm sequences occurred within 14 days of the significant transient eastward GNSS displacements. The earthquake swarms that were associated with significant transient eastward GNSS displacements were potentially indicative of small SSEs that had previously escaped detection. It is also worth noting that significant transient displacements were not always accompanied by earthquake swarms. For example, 21 of the 30 significant transient displacements recorded at station GISB were not associated with the detected earthquake swarms, which suggests that the SSEs in the Hikurangi Trench are not always accompanied by $M \geq 3$ earthquake swarms. However, it is possible that smaller earthquake swarms $(M<3)$ accompany these SSEs as reported by Shaddox and Schwartz (2019).

We detected 31 recurrent earthquake swarm sequences in four regions $\left(38.2^{\circ} \mathrm{S}, 38.9^{\circ} \mathrm{S}, 39.3^{\circ} \mathrm{S}, 39.8^{\circ} \mathrm{S}\right.$, and $40.7^{\circ} \mathrm{S}$ along the east coast of the North Island; inside the cyan squares in Figures 6 and S1) from January 1997 through December 2015. We detected 20 of the 31 recurrent earthquake swarm sequences during the period when the nearby GNSS stations were in operation. Ten of the 20 recurrent earthquake swarms were associated with previously identified large SSEs (Wallace \& Beavan, 2010; Wallace \& Eberhart-Phillips, 2013; Wallace et al., 2012, 2016). Five of the remaining 10 recurrent earthquake swarms occurred within 14 days before and after transient eastward GNSS displacements. These results suggest many of, but not all of, the recurrent earthquake swarms were associated with SSEs.

We checked the depth of the 31 recurrent earthquake swarm sequences to see whether the recurrent earthquake swarms were located within the subducting plate or overriding plate. We excluded earthquake swarm events whose depth uncertainty was large ( $5 \mathrm{~km}$ or larger) or whose depth had been assigned by an operator. We found that 111 (89\%) of the 125 events constituting the recurrent earthquake swarm sequences are deeper than the plate interface whereas 14 (11\%) of the 125 events are shallower than the plate interface. These results suggest that most of the recurrent earthquake swarm sequences are located within the subducting plate. On the other hand, 13 of the 14 events shallower than the plate interface occurred in the proximity of station PUKE $\left(38.1^{\circ} \mathrm{S}\right.$ and $178.3^{\circ} \mathrm{E}$; see the red triangle in Figures $6 \mathrm{a}$ and $\left.6 \mathrm{~b}\right)$. Five of the 13 events located close to station PUKE are shallower than the plate interface even when considering the depth uncertainty. These imply that characteristic structures that facilitate the recurrence of earthquake swarms exist not only within the subducting plate but also within the overriding plate in the proximity of station PUKE.

We analyzed 49 earthquake swarm-transient GNSS displacement pairs to identify the SSEs that were potentially accompanied by earthquake swarms (see Section 2.4). Here, we removed one earthquake 

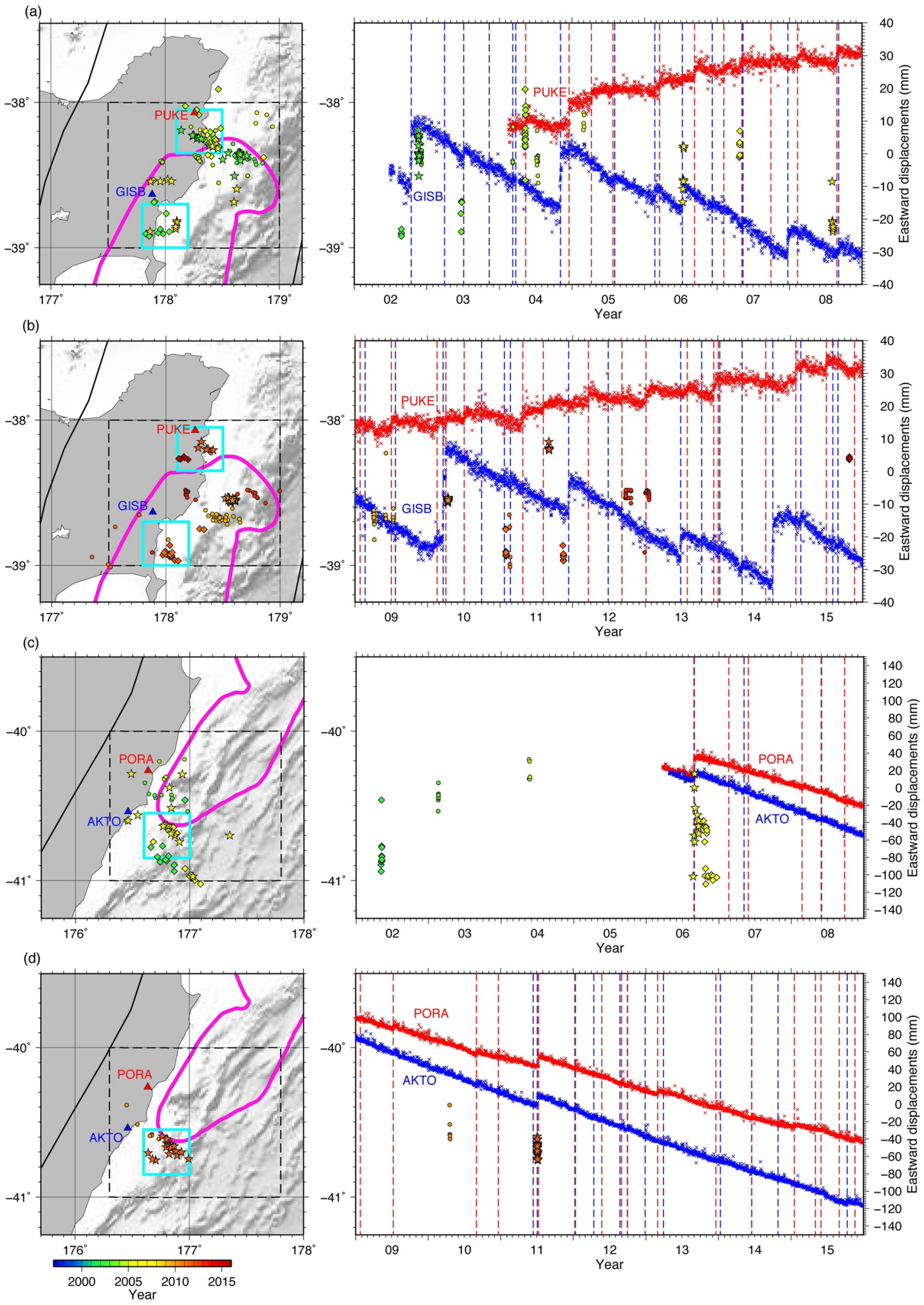
swarm-transient GNSS displacement pair because we found that the transient GNSS displacement was associated with not an SSE but the December $2007 M_{w} 6.7$ off Gisborne earthquake. We found that 16 of the 49 pairs were associated with transient GNSS displacements due to the SSEs detected by previous studies (Wallace \& Beavan, 2010; Wallace \& Eberhart-Phillips, 2013; Wallace et al., 2012, 2016).

Examples of the pairs associated with known SSEs are shown in Figure 7. We found that the occurrence time of a given earthquake swarm relative to a transient GNSS displacement substantially varied among the SSEs. An earthquake swarm started 2 days after a transient displacement that was associated with the July $2006 M_{w} 6.6$ Gisborne SSE (Figure 7a). The August-September $2006 M_{w} 6.9$ south Hawke's Bay SSE was accompanied by four earthquake swarm sequences (Figure 7b). The first earthquake swarm (cluster $A$ ) occurred 13-11 days before a transient displacement that was recorded at station AKTO, and preceded the SSE. The second earthquake swarm (cluster $B$ ) began 8 days before the displacement and ended 4 days after the displacement. Here, the date of the displacement is defined as the date with the minimum $\triangle$ AIC value and the duration of the transient displacement is not considered. The third and fourth earthquake swarms (clusters $C$ and $D$ ) began 15 and 45 days after the displacement, respectively, with each showing clear delays with respect to the SSE. An earthquake swarm also occurred two days after the onset of the September-October $2011 M_{w} 6.2$ Tolaga Bay SSE (Figure 7c). This SSE continued for over a month, which is much longer than the duration of the accompanying earthquake swarm (less than a day), implying that the correlation between the earthquake swarm and SSE durations is weak.

Examining the remaining 33 of the 49 earthquake swarm-transient GNSS displacement pairs, we identified 23 possible new SSEs. We listed the 23 possible SSEs in the supporting information (Data Set S2). We present example earthquake swarm-transient GNSS displacement pairs that are potentially associated with new SSEs in Figure 8. As in Figure 7, there is often significant variability between the occurrence time of a given earthquake swarm and transient GNSS displacement. The two earthquake swarms (clusters $A$ and $B$ ) in Figure 8a preceded a transient displacement by $\sim 25$ and 6 days, respectively. An earthquake swarm presented in Figure $8 \mathrm{~b}$ began three days after a small eastward displacement of $1.0 \mathrm{~mm}$ at station CKID in April 2012. We also observed the clear delay of an earthquake swarm that occurred 14 days after a transient displacement at station KOKO in November 2005 (Figure 8c).

We present three more examples of earthquake swarms preceding a transient GNSS displacement in Figure 9. These three earthquake swarms began 15,14 , and 19 days, respectively, before the transient displacements that were potentially associated with the new SSEs. We note that these three earthquake swarms ceased more than a week before a transient displacement. This implies that the earthquake swarms ceased before the onset of an SSE and that their seismicity rate was insensitive to the SSE slip rate and slip amount.

We estimated fault models for the potential SSEs that caused the displacements in Figure 8a (off Gisborne in February 2011), Figure 9b (off Tolaga Bay in May 2007), and Figure 9c (near Mahia Peninsula in October 2013) via the grid search method. The estimated moment magnitudes of these potential SSEs were 6.2, 6.4, and 6.2, respectively which were relatively small compared with the SSEs in the existing catalogs (Wallace \& Beavan, 2010; Wallace \& Eberhart-Phillips, 2013; Wallace et al., 2012, 2016). We tried to model six more possible new SSEs. However, the daily GNSS displacements associated with the possible new SSEs were generally small and incoherent. Therefore, it was difficult for us to constrain the fault models of the possible SSEs well. We showed the remaining six possible SSE fault models in Figures S2 and S3. In addition, we compared the locations of the 23 possible new SSEs to those of the previously documented large SSEs (see supporting information S2), to find that their locations are similar.

Figure 6. Comparison between the detected earthquake swarms and GNSS daily time series. (a and b) Comparison between the detected earthquake swarms and the east-west component of the GNSS daily time series at stations PUKE (red) and GISB (blue) for the January 2002-December 2008 and January 2009-December 2015 periods, respectively. The dashed colored lines in the time series indicate the dates of significant transient eastward displacements. The small circles are the detected earthquake swarms, which are color-coded according to the occurrence time. We selected the earthquake swarm sequences whose centroids were located inside the regions indicated by black dashed rectangles in the map views. The colored stars are the earthquake swarms associated with the SSEs in existing catalogs. The cyan squares indicate regions where we observed recurrent earthquake swarms. The colored diamonds are the earthquake swarm sequences whose centroids were located inside the cyan squares. The thick magenta contours in the map views indicate the 50-mm total slip contour for the 2002-2010 shallow SSEs (Wallace \& Beavan, 2010). (c and d) Comparison between the detected earthquake swarms and the east-west component of the GNSS daily time series at stations PORA (red) and AKTO (blue). The symbols in (c and d) are the same as in (a and b), respectively. GNSS, global navigation satellite system; SSE, slow slip events. 

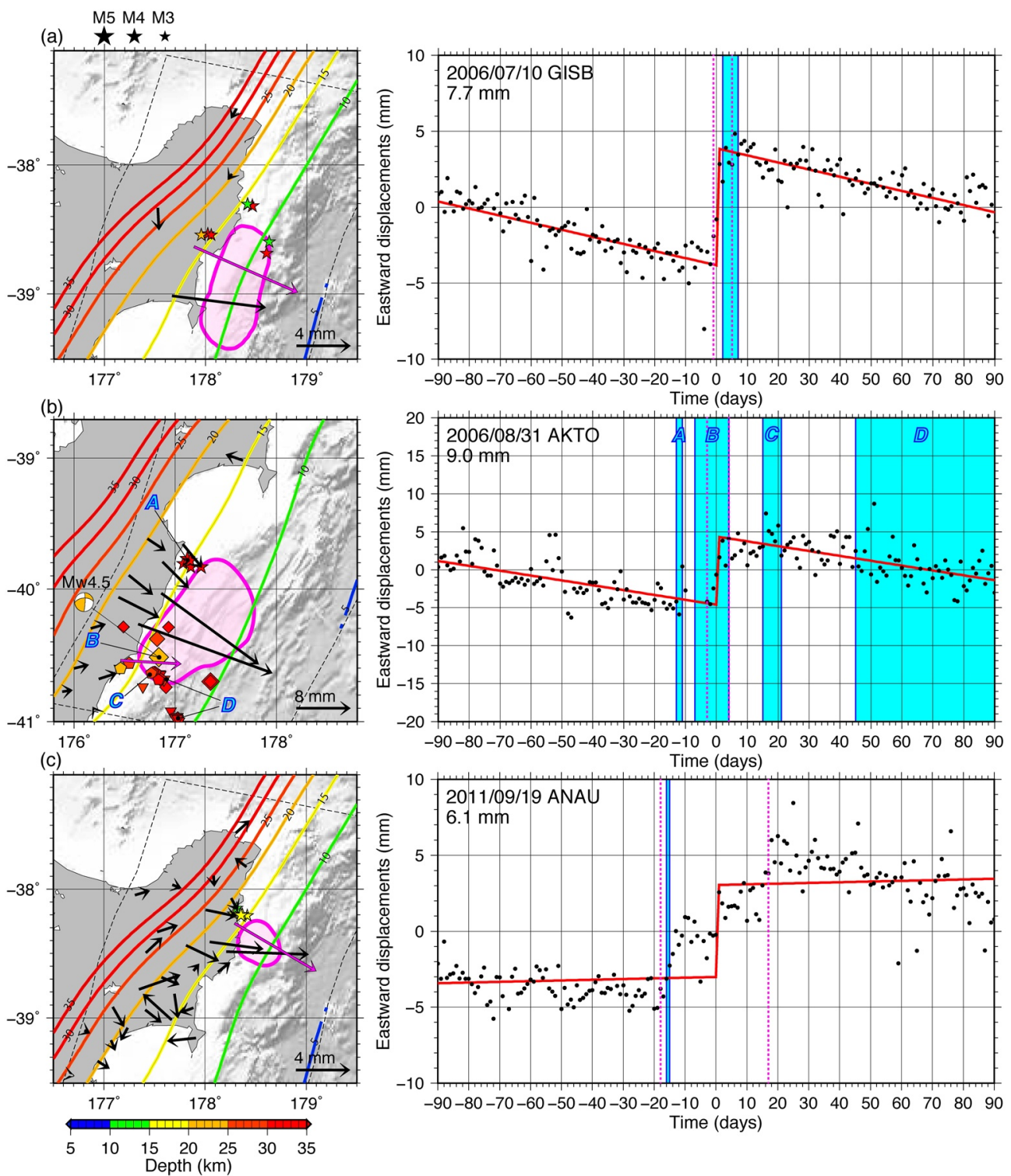

Figure 7. Example earthquake swarm-transient GNSS displacement pairs associated with known SSEs. (a) An earthquake swarm sequence and significant transient GNSS displacement associated with the July $2006 M_{w} 6.6$ Gisborne SSE. The left panel is a map view of the earthquake swarm events (stars), observed GNSS daily displacements (black arrows), and SSE source region (magenta shaded area). The earthquake swarm events are color-coded according to depth. The magenta arrow indicates the paired transient GNSS displacement. The colored contours are depth contours of the subducting plate interface (5-km interval). The right panel shows GNSS daily coordinates (black points) for a 180-days moving time window at the station indicated by the magenta arrow (GISB). The red line is a fitted linear function with an offset. The occurrence period of the earthquake swarm is indicated by the cyan shaded area. The two dashed magenta lines indicate the onset and end of the SSE. (b) Four earthquake swarm sequences and a significant transient GNSS displacement associated with the August-September $2006 M_{w} 6.9$ south Hawke's Bay SSE. The four earthquake swarms are named clusters $A-D$, and are indicated by different symbols. Clusters $B-D$ are paired with the transient displacement indicated by the magenta arrow. Cluster $A$ is paired with a transient displacement at a different station (CKID: $39.658^{\circ} \mathrm{S}, 177.076^{\circ} \mathrm{E}$ ). (c) An earthquake swarm sequence and significant transient GNSS displacement associated with the September-October $2011 M_{w} 6.2$ Tolaga Bay SSE. The symbols are the same as in (a). The source regions and occurrence periods of the SSEs in (a-c) are from Wallace and Beavan (2010), and Wallace et al. (2012). GNSS, global navigation satellite system; SSE, slow slip events. 

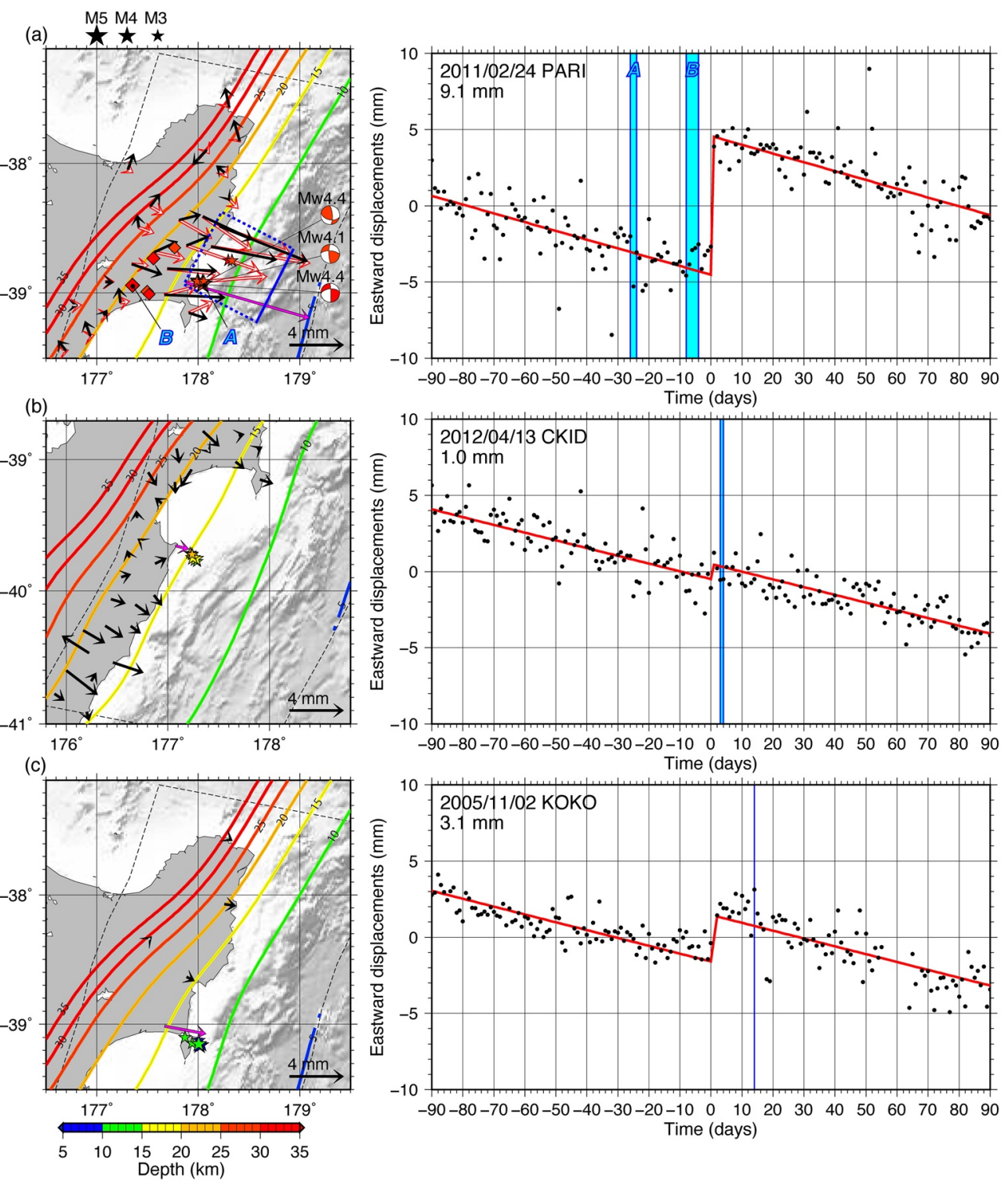

Figure 8. Example earthquake swarm-transient GNSS displacement pairs. (a) A significant transient GNSS displacement observed on February 24, 2011 and 2 nearby earthquake swarm sequences. The left panel is a map view of two earthquake swarms (clusters $A$ and $B$ ), which are indicated by different symbols, and the observed GNSS daily displacements (black arrows). The earthquake swarms are color-coded according to depth. Cluster $A$ is paired with the transient displacement represented by the magenta arrow (PARI). Cluster $B$ is paired with a transient displacement at a different station (PRTU: $38.814^{\circ} \mathrm{S}$ and $177.698^{\circ} \mathrm{E}$ ). The blue dashed square shows the location of the estimated fault of the possible SSE $\left(M_{w} 6.2\right)$, with the blue solid line representing the upper edge of the fault. The white solid arrows that are outlined in red indicate the calculated surface displacements due to slip along the fault. The colored contours are depth contours of the subducting plate interface (5-km interval). The right panel shows the GNSS daily coordinates (black points) for a 180-days moving time window at the station indicated by the magenta arrow (PARI). The red line is a fitted linear function with an offset. The occurrence periods for the earthquake swarms are indicated by the cyan shaded areas. (b) A significant transient GNSS displacement observed on April 13, 2012 and a nearby earthquake swarm sequence. (c) A significant transient GNSS displacement observed on November 2, 2005 and a nearby earthquake swarm sequence. The symbols are the same as in (a). GNSS, global navigation satellite system; SSE, slow slip events. 

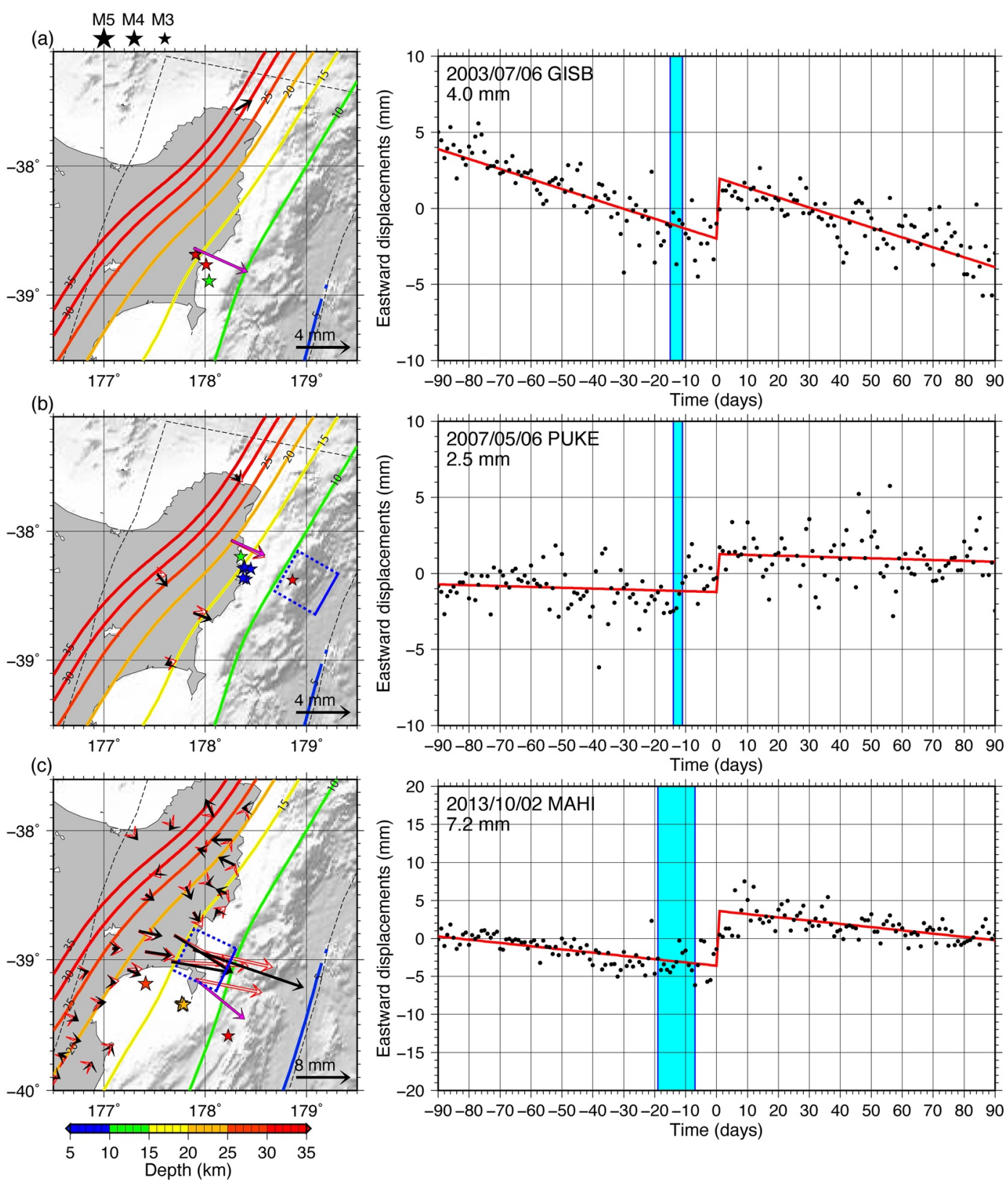

Figure 9. Examples of earthquake swarms preceding a transient GNSS displacement. (a) An earthquake swarm sequence preceding a significant transient GNSS displacement observed on July 6, 2003. The left panel is a map view of the earthquake swarm events (stars) and observed GNSS daily displacements (black arrows). The earthquake swarm events are color-coded according to depth. The magenta arrow indicates the paired transient GNSS displacement (GISB). The colored contours are depth contours of the subducting plate interface (5-km interval). The right panel shows the GNSS daily coordinates (black points) for a 180-days moving time window at the station indicated by the magenta arrow (GISB). The red line is a fitted linear function with an offset. The occurrence period of the earthquake swarm is indicated by the cyan shaded area. (b) An earthquake swarm sequence preceding a significant transient GNSS displacement observed on May 6, 2007. The blue dashed square shows the location of the estimated fault of the possible SSE $\left(M_{w} 6.4\right)$, with the blue solid line representing the upper edge of the fault. The white solid arrows that are outlined in red indicate the calculated surface displacements due to slip along the fault. (c) An earthquake swarm sequence preceding a significant transient GNSS displacement observed on October 2, 2013. The blue dashed square shows the location of the estimated fault of the possible SSE $\left(M_{w} 6.2\right)$. The other symbols are the same as in (a and b). GNSS, global navigation satellite system; SSE, slow slip events. 

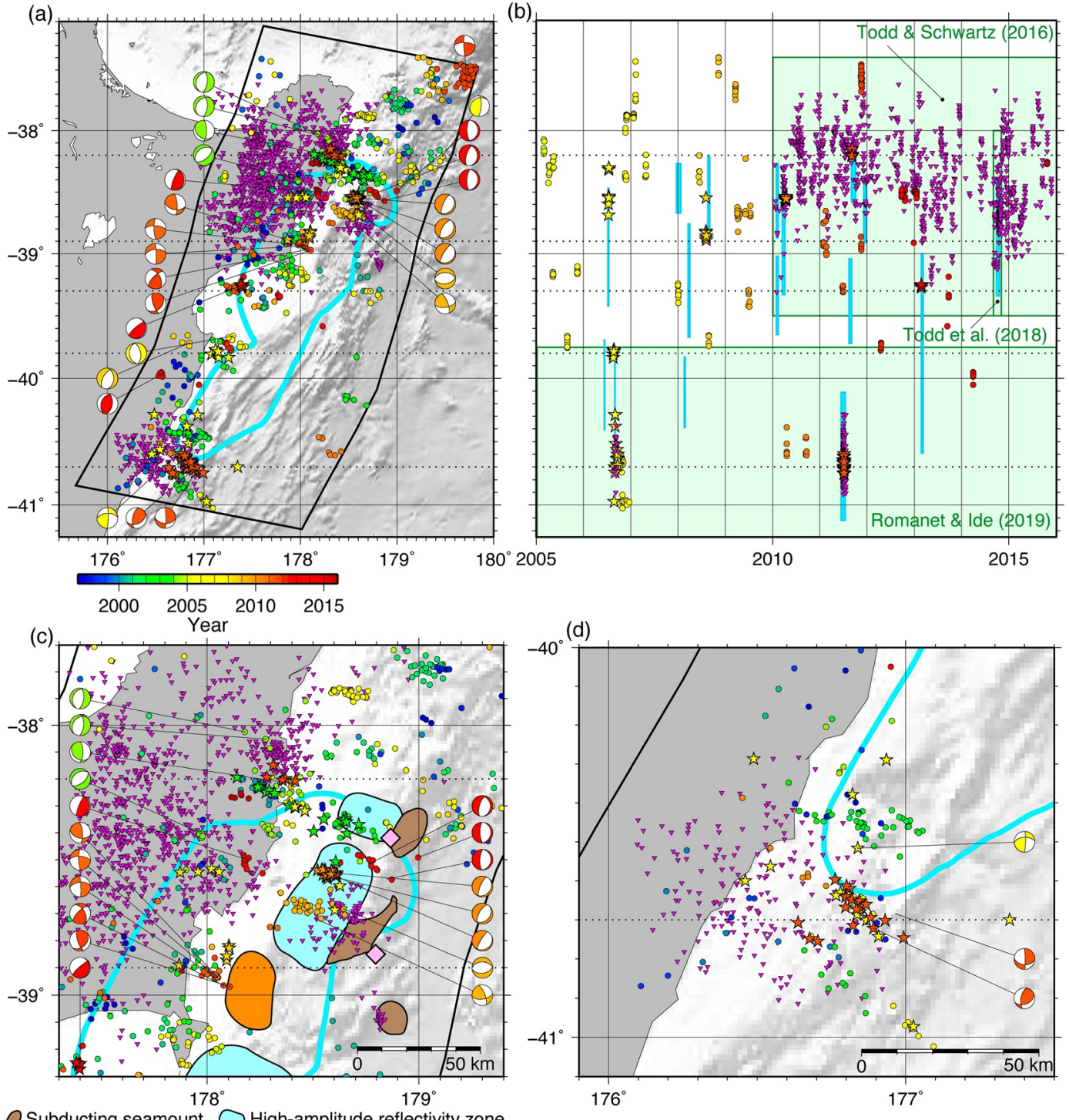

Subducting seamount $\bigcirc$ High-amplitude reflectivity zone

Lens reflectivity zone $\diamond 1947 \mathrm{Mw} 7.2$ and 7.1 tsunami earthquakes

Figure 10. Spatiotemporal distribution of the earthquake swarms and tectonic tremors. (a) Epicentral distribution of the earthquake swarms and tectonic tremors. The small circles are the detected swarms, which are color-coded according to their occurrence times. The colored stars indicate the earthquake swarms associated with the SSEs in existing catalogs. The colored beach-ball diagrams are the focal mechanisms for swarm events. The small magenta inverted triangles indicate tectonic tremors. The thick cyan contour is the 50-mm total slip contour for the 2002-2010 shallow SSEs (Wallace \& Beavan, 2010). (b) Longitude-time diagram of the earthquake swarms and tectonic tremors. The green shaded areas indicate the spatiotemporal coverage of the tectonic tremor catalogs (Romanet \& Ide, 2019; Todd et al., 2018; Todd \& Schwartz, 2016). The cyan lines denote the spatiotemporal extents of the SSEs detected by previous studies (Wallace \& Beavan, 2010; Wallace \& Eberhart-Phillips, 2013; Wallace et al., 2012, 2016). (c and d) Enlarged views of the epicentral distribution of the earthquake swarms and tectonic tremors in (a). The seismically reflective zones and subducting seamounts along the plate boundary in (c) are adapted from Bell et al. (2010) and Barker et al. (2018). Please refer to (a) and the legend in (c) for an explanation of the symbols. SSE, slow slip events.

\subsection{Comparison Between Earthquake Swarms and Tectonic Tremors}

We compared our earthquake swarm catalog with three tectonic tremor catalogs (Romanet \& Ide, 2019; Todd et al., 2018; Todd \& Schwartz, 2016), with a focus on the tectonic tremors in the shallow part of the Hikurangi Trench. The spatiotemporal coverage of the tremor catalogs is shown in Figure 10b. We found that many of the tectonic tremor epicenters were located inland, whereas the earthquake swarm epicenters 
were predominotly located along the east coast of the North Island (Figure 10a). The inland earthquake swarms were quite sparse, as illustrated in Figure 3b. The epicenters of the earthquake swarms and tectonic tremors were complementarily distributed, even when considering the large epicentral errors of the tectonic tremors ( $\sim 10 \mathrm{~km}$; Figures 10c and 10d). A comparison of the earthquake swarm and tectonic tremor occurrence times indicated that the two tremor episodes in the southern part of the study region $\left(40^{\circ} \mathrm{S}-41^{\circ} \mathrm{S}\right.$; Figures $10 \mathrm{~b}$ and 10d) were accompanied by earthquake swarms, although many tectonic tremor episodes in the northern part $\left(37.5^{\circ} \mathrm{S}-39.5^{\circ} \mathrm{S}\right.$; Figures $9 \mathrm{~b}$ and $\left.9 \mathrm{c}\right)$ occurred without earthquake swarms.

We compared the structural heterogeneity (i.e., seismically reflective zones and subducting seamounts) along the plate boundary that was imaged by a seismic reflection survey (Bell et al., 2010) and magnetic anomaly data analysis (Barker et al., 2018) to the epicenters of the earthquake swarms and tectonic tremors in Figure 10c. While the tectonic tremors were located proximal to subducting seamounts (Todd et al., 2018), there was no clear correlation between the detected earthquake swarms and structural heterogeneity. The detected earthquake swarms were distributed both inside and outside of high-amplitude reflectivity zones. There does not appear to be a correlation between the epicenters of the detected earthquake swarms $(M \geq 3)$ and the locations of subducting seamounts. However, Shaddox and Schwartz (2019) observed swarm-like microseismicity $(-1 \leq M<2)$ above the subducting seamount located at $38.8^{\circ} \mathrm{S}$ and $178.7^{\circ} \mathrm{E}$ after the September-October $2014 M_{w} 6.8$ Gisborne SSE. Therefore, it is possible that the epicentral distribution of smaller earthquake swarms $(M<3)$ correlates to structural heterogeneity along the plate boundary.

We then compared the spatiotemporal distribution of the earthquake swarms and tectonic tremors for individual SSEs. Two examples of SSEs accompanied by both earthquake swarms and tectonic tremors are provided in Figures 11a and 11b. The earthquake swarms and tectonic tremors are spatially distributed either on the periphery of or outside of the source regions of the August-September $2006 M_{w} 6.9$ south Hawke's Bay and March-April $2010 M_{w} 6.7$ Gisborne SSEs (Figures 11a and 11b, respectively). This tendency was also visible for the earthquake swarms in Figure 7. We note that the tectonic tremors are located inland compared to the earthquake swarm locations in Figures 11a and 11b, which is consistent with observations shown in Figures 10c and 10d. The occurrence times of the earthquake swarms relative to those of the tectonic tremors varies for individual SSEs (Figure 11a and 11b). An earthquake swarm sequence near station CKID preceded the August-September 2006 south Hawke's Bay SSE (see also Figure 7b) and tectonic tremors by $\sim 10$ days. We observed both an earthquake swarm sequence and tectonic tremors near station AKTO during this SSE. An October-December 2006 earthquake swarm sequence near station AKTO showed a clear delay with respect to the SSE and tectonic tremors. We only observed inland tectonic tremors during the March-April 2010 Gisborne SSE (Figures 11b), with offshore normal-faulting earthquake swarms observed $\sim 10$ days after the end of the SSE.

We present the earthquake swarms and tectonic tremors that were potentially associated with a new SSE in Figures 11c. We observed coherent eastward GNSS displacements at stations WMAT, PUKE, and ANAU from December 2012 to late January 2013. Two earthquake swarm sequences that coincided with the eastward GNSS displacements occurred to the south of station ANAU during December 29, 2012 to January 9, 2013 and January 17-20, 2013. We also observed temporal clustering of tectonic tremors in December 2012, January 2013, and February 2013. The temporal clustering in January 2013 coincided with the 17-20 January earthquake swarm sequence.

\subsection{Comparison Between the Tectonic Tremors and Transient GNSS Displacements}

We investigated the occurrence times of the tectonic tremors relative to transient GNSS displacements in the same manner as the earthquake swarm analysis, to further compare the earthquake swarms and tectonic tremors (see Sections 2.4 and 3.3). We formed tectonic tremor-significant transient GNSS displacement pairs for the analysis, using the GNSS displacement that was recorded at the closest station to the epicenter of a given tremor and occurred most closely in time to the occurrence of that tremor. We required that a tremor had to occur within 90 days of a transient displacement. Note that a transient GNSS displacement can be paired with multiple tremors. Here, we disregarded the tremors whose epicenters were far from the GNSS stations (i.e., more than $60 \mathrm{~km}$ away from the closest GNSS station). This resulted in 171 significant transient GNSS displacements being paired with tectonic tremors. 

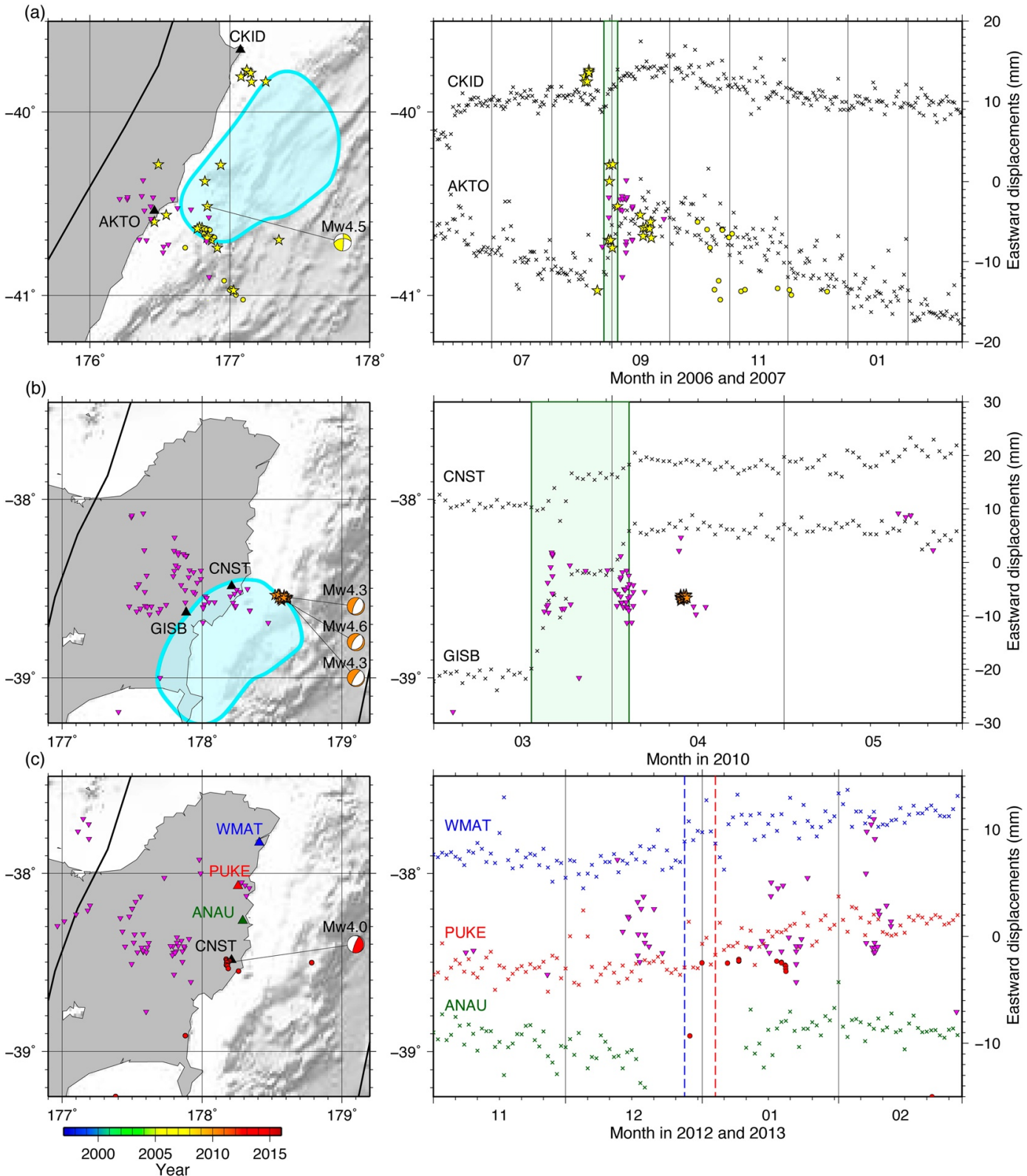

Figure 11. Spatiotemporal distribution of earthquake swarms and tectonic tremors for individual SSEs. (a) Earthquake swarms and tectonic tremors accompanying the August-September $2006 M_{w} 6.9$ south Hawke's Bay SSE. The left panel shows the epicenters of the earthquake swarm events (small circles), the earthquake swarms associated with the SSEs in existing catalogs (colored stars; see Section 3.1), tectonic tremors (small magenta inverted triangles), and the source region of the SSE (cyan shaded area). The earthquake swarm events are color-coded according to occurrence time. The right panel shows the GNSS daily coordinates (black crosses) at the stations indicated by the black triangles in map view (CKID and AKTO). The number for a given month represent the middle of the month. The green shaded area denotes the occurrence period of the SSE. (b) Earthquake swarms and tectonic tremors accompanying the March-April $2010 M_{w} 6.7$ Gisborne SSE. The source regions and occurrence periods of the SSEs in (a and b) are from Wallace and Beavan (2010). (c) Earthquake swarms and tectonic tremors that were potentially associated with a new December 2012-January 2013 SSE. The dashed colored lines in the time series indicate the dates of significant transient eastward displacements recorded at stations WMAT and PUKE. We could not determine the precise date of the significant transient eastward displacement at station ANAU because the GNSS daily coordinates at station ANAU are not available from December 20, 2012 through January 10, 2013. We did not model this possible SSE because we did not observe a significant transient eastward displacement at the closest GNSS station to the centroid of the earthquake swarms (CNST; the black triangle) and thus this event did not satisfy the requirement for our SSE fault modeling (see Section 2.4). The other symbols are the same as in (a). GNSS, global navigation satellite system; SSE, slow slip events. 

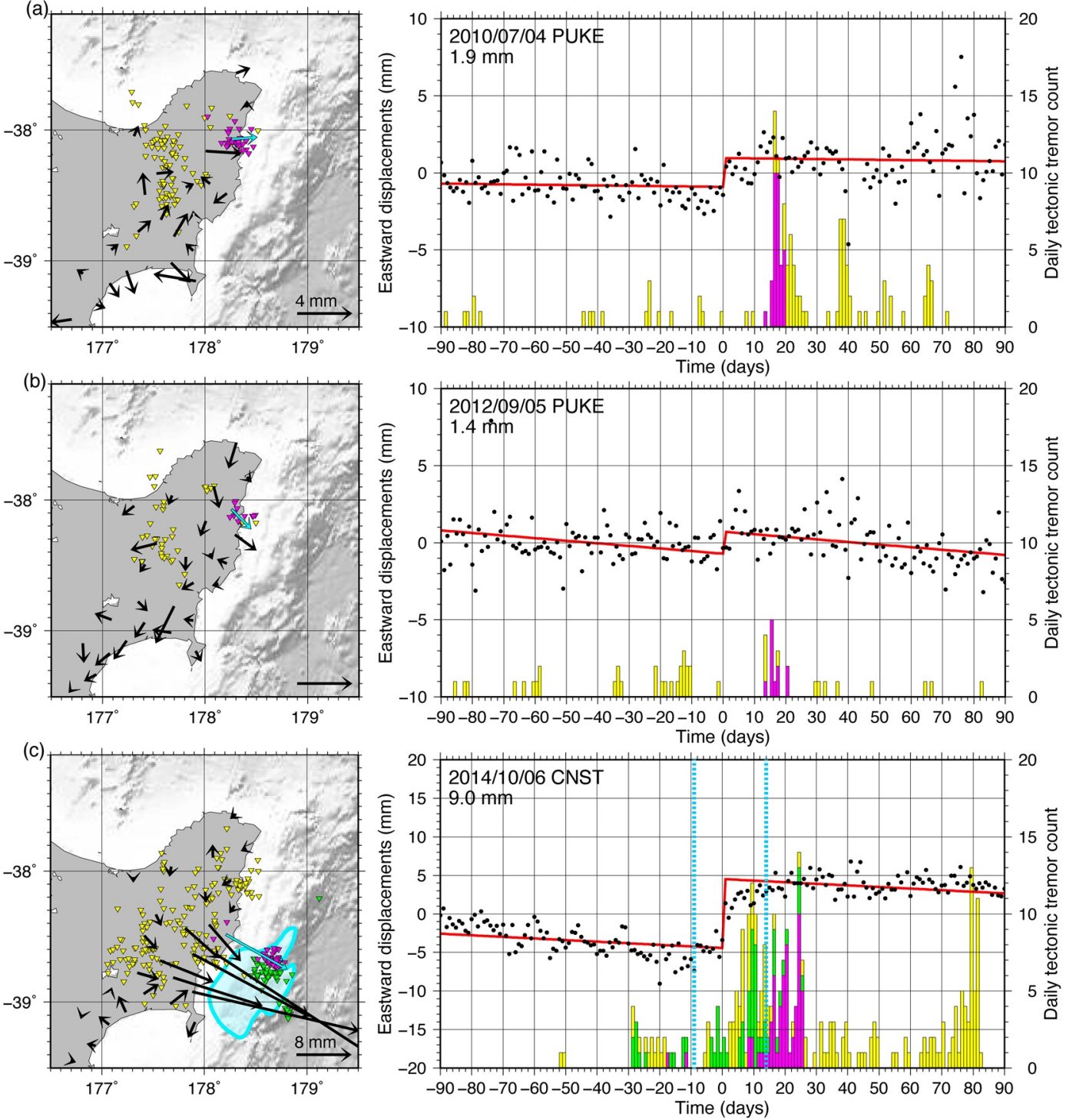

Figure 12. Tremor bursts that were delayed with respect to a transient GNSS displacement. (a) A tremor burst that was delayed with respect to a transient GNSS displacement that was observed on July 4, 2010. The left panel shows the observed GNSS daily displacements (black arrows), transient GNSS displacement paired with tremors (cyan arrow), paired tectonic tremors (small magenta inverted triangles), and other tectonic tremors (yellow inverted triangles). The right panel shows the GNSS daily coordinates (black points) for a 180-days moving time window at the station indicated by the cyan arrow (PUKE). The red line is a fitted linear function with an offset. The histogram shows the daily tremor counts for the paired (magenta) and other (yellow) tremors. (b) A tremor burst that is delayed with respect to a transient GNSS displacement observed on September 5, 2012. (c) A tremor burst that is delayed with respect to a transient GNSS displacement observed on October 6, 2014. The cyan shaded area in the map view indicates the source region of the September-October $2014 M_{w} 6.8$ Gisborne SSE (Wallace et al., 2016). Green inverted triangles indicate offshore tremors located by Todd et al. (2018). The histogram in the right panel shows the daily tremor counts for the paired (magenta) and other (yellow and green) tremors. The onset and end of the SSE are indicated by the thick cyan dashed lines (Wallace et al., 2016). The other symbols are the same as those in (a). GNSS, global navigation satellite system; SSE, slow slip events.

In contrast to the earthquake swarms (Figure 9), we did not observe any tremor bursts that occurred in the range 5-25 days before a transient GNSS displacement. We define a tremor burst as a peak in the daily tremor count within 90 days of a transient GNSS displacement. We also required at least five tremors to occur in a given day. We observed that there was a delay in tremor bursts with respect to the transient GNSS displacements, as is shown in Figure 12. A tremor burst was delayed by 24 days with respect to a significant 

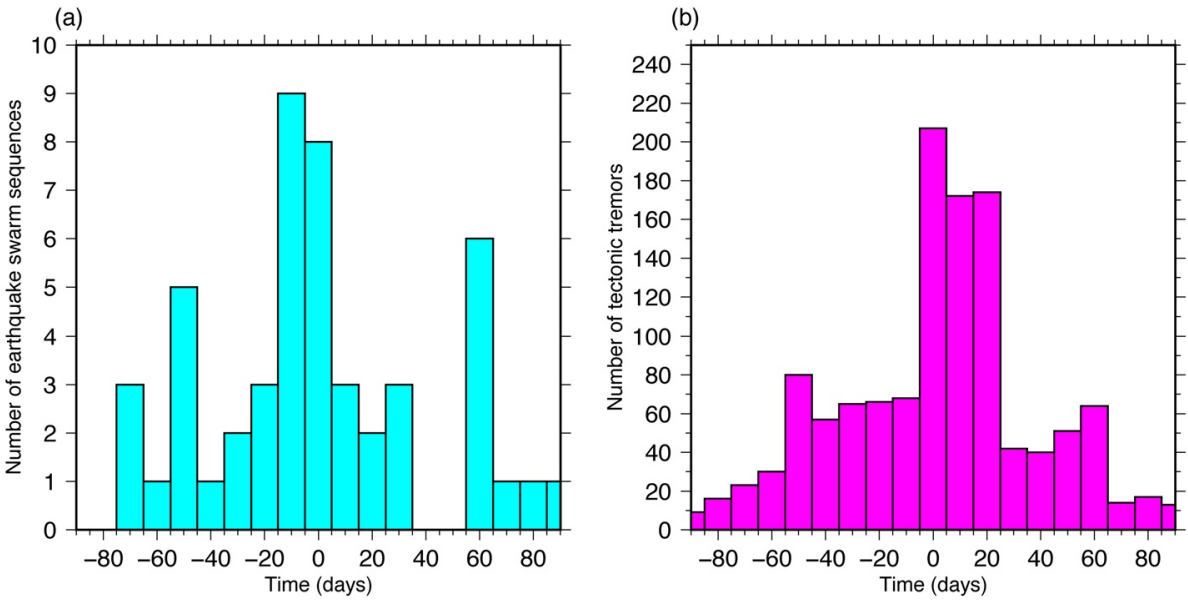

Figure 13. Histograms of the occurrence times of the (a) earthquake swarms and (b) tectonic tremors relative to a transient GNSS displacement. GNSS, global navigation satellite system.

transient displacement due to the September-October $2014 M_{w} 6.8$ Gisborne SSE (Figure 12c), as pointed out by Todd et al. (2018) and Shaddox and Schwartz (2019). We found that the tremor bursts located directly below station PUKE in July 2010 and September 2012 were delayed by 16 and 15 days with respect to the transient GNSS displacements, respectively (Figures 12a and 12b).

We showed the histograms of the occurrence times of the earthquake swarm sequences (Figure 13a) and tectonic tremors (Figure 13b) relative to the transient GNSS displacements for all the pairs. Here we defined the occurrence time of an earthquake swarm sequence as the center of the occurrence period of the earthquake swarm sequence. We observed that 358 of the 1208 tectonic tremors were delayed by 5-25 days with respect to a transient GNSS displacement, whereas 147 of the 1208 tectonic tremors (less than half of the delayed tremors) preceded a transient GNSS displacement by 5-25 days (Figure 13b). An opposite tendency was observed for the earthquake swarms (Figure 13a). Five of the 49 earthquake swarm sequences were delayed by 5-25 days with respect to a transient GNSS displacement, whereas 12 of the 49 earthquake swarm sequences preceded a transient GNSS displacement by 5-25 days. The proportion of tremors that were delayed by 5-25 days (30\%) is larger than the proportion of earthquake swarms that were delayed by 5-25 days (10\%). Conversely, the proportion of earthquake swarms preceding a transient GNSS displacement by 5-25 days (24\%) is larger than the proportion of tremors preceding a transient GNSS displacement by 5-25 days (12\%). However, the small number of the earthquake swarm sequences (49 samples) prevented us from conducting a statistical analysis. More observations are needed to conclude that the above tendencies are robust and statistically significant.

\section{Discussion}

\subsection{Earthquake Swarm Triggering Mechanism in the Hikurangi Trench}

The characteristics of earthquake swarms in the Hikurangi Trench are strikingly different from the characteristics of earthquake swarms in other subduction zones, such as the Boso-Oki region of eastern Japan. Specifically, the earthquake swarms in the Hikurangi Trench and Boso-Oki region are different with respect to their focal mechanisms, occurrence times relative to related SSEs, and their association with tectonic tremors. The earthquake swarms in the Boso-Oki region have low-angle reverse fault mechanisms and are located along the plate interface, with seismicity rates that are well correlated with SSE slip rates along the plate interface (Fukuda, 2018) and no observed occurrence time difference of more than several days between the earthquake swarms and SSEs. Furthermore, the earthquake swarms in the Boso-Oki region are not accompanied by detectable tectonic tremors. Conversely, most of the earthquake swarms in the Hikurangi Trench are intraplate (mostly intraslab) events (Figure 4). Occurrence time differences of more than several days between the earthquake swarms and SSEs are often observed (Figure 7-9 and 13a). Furthermore, tectonic tremors were found to sometimes accompany the earthquake swarms 


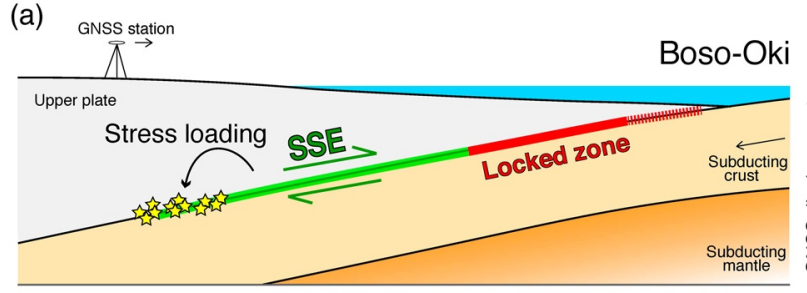

(b)

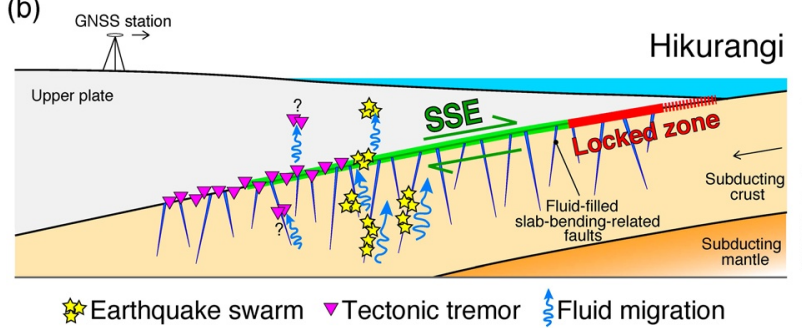

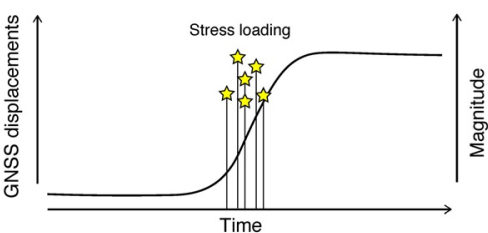

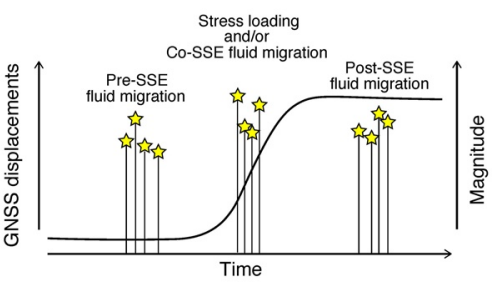

Figure 14. Two earthquake swarm triggering mechanisms in subduction zones. (a) Earthquake swarm triggering via SSE-induced stress loading. This mechanism is plausible for the earthquake swarms in the Boso-Oki region of eastern Japan (Fukuda, 2018). (b) Earthquake swarm triggering via pre- and/or post-SSE fluid migration. We prefer this triggering mechanism to explain the generation of earthquake swarms in the Hikurangi Trench. Pressurized fluids accumulate within the subducting slab prior to the onset of SSEs and drain after the SSEs (Warren-Smith et al, 2019). This accumulation of pressurized fluids sometimes breaks a low-permeability seal, with the fluid then beginning to migrate along preexisting intraplate faults (pre-SSE fluid migration), triggering pre-SSE earthquake swarms. The occurrence of an SSE along the plate boundary enhances the permeability of the surrounding rocks and induces postSSE fluid migration, which in turn triggers post-SSE earthquake swarms. Co-SSE earthquake swarms are triggered by SSE-induced stress loading and/or co-SSE fluid migration. Please refer to legends within the figure for the symbol descriptions. SSE, slow slip events.

(Figure 11). Earthquake swarms neighboring a tremor-genic region have also been observed in the northern $\left(39^{\circ} \mathrm{N}-40^{\circ} \mathrm{N}\right)$ and southern $\left(36^{\circ} \mathrm{N}-37^{\circ} \mathrm{N}\right)$ parts of the Japan Trench (Nishikawa et al., 2019). However, these earthquake swarms are low-angle reverse fault events that are located along the plate interface (Nishikawa \& Ide, 2018), and therefore differ from the earthquake swarms in the Hikurangi Trench.

The striking differences between earthquake swarm characteristics in the Hikurangi Trench and Boso-Oki region implies differences in the earthquake swarm triggering mechanisms in these two areas. Fukuda (2018) proposed that earthquake swarms in the Boso-Oki region were triggered by SSE-induced stress loading, based on a strong correlation between earthquake swarm seismicity rates and SSE slip rates (Figure 14a). However, SSE-induced stress loading cannot fully explain the earthquake swarms in the Hikurangi Trench. In this study, we often observed earthquake swarms that either preceded or succeeded a given transient GNSS displacement by more than several days (Figures 7-9). Furthermore, earthquake swarms sometimes ceased more than a week before a given transient GNSS displacement (Figure 9). These observations suggest that the earthquake swarm seismicity rates in the Hikurangi Trench are not correlated with SSE slip or stress loading rates.

Another triggering mechanism is necessary to explain the observations of earthquake swarms either preceding or succeeding a given SSE. A possible mechanism is fluid migration within the subducting or upper plate (Figure 14b). Using an earthquake focal mechanism analysis, Warren-Smith et al. (2019) inferred that there was a build-up of fluid pressure within the subducting slab before SSEs in the Hikurangi Trench. Such an accumulation of pressurized fluids may break a low-permeability seal (Tenthorey et al., 2003), allowing fluid migration along preexisting intraplate faults prior to an SSE (Figure 14b), which reduces the shear strength of the faults (e.g., Raleigh et al., 1976; Yamashita, 1998) and potentially triggers pre-SSE earthquake swarms. Furthermore, the occurrence of an SSE along the plate boundary enhances the permeability of the surrounding rocks via strain-induced fracture opening (Rivet et al., 2011). This may induce fluid movement/drainage from intraslab faults to the plate boundary and overriding plate after an SSE has occurred (Warren-Smith et al., 2019). Such post-SSE fluid migration may potentially trigger post-SSE 
earthquake swarms (Figures 7b, 8c, 11b, and 14b). We speculate that the intraplate structures that facilitate the recurrence of earthquake swarms, which were implied in Figures 4, 6, and S1, may be fluid conduits.

Shaddox and Schwartz (2019) invoked fluid drainage into the upper plate following an SSE to explain the delay in microseismicity above a subducting seamount with respect to the September-October 2014 Gisborne SSE. Based on microseismic observations of burst-type repeating earthquakes, they further suggested that fluid drainage into the overriding plate triggered SSEs on multiple faults within a fracture network of the upper plate. However, it is unclear whether the pre- and post-SSE earthquake swarms that we observed (Figures 7-9) in this study were also associated with SSEs on multiple intraplate faults. Further analyses such as repeating earthquake detection are needed to verify this hypothesis.

If fluids ascending from the subducting plate trigger earthquake swarms (Figure 14b), one may expect a correlation between earthquake swarm depths and their lag time relative to the plate boundary SSEs. We checked the depth of events constituting the earthquake swarm sequences paired with transient eastward GNSS displacements in order to see whether there is any relationship between earthquake swarm depths and their lag time. We excluded events whose depth uncertainty was large ( $5 \mathrm{~km}$ or larger) or whose depth had been assigned by an operator. We then compared the depth of the 203 earthquake swarm events to their lag time relative to the transient eastward GNSS displacements. However, we observed no clear correlation between them (Figure S4). This is contrary to our expectations. On the other hand, we found that even earthquake swarms located close to the plate interface can have a long lag time relative to plate boundary SSEs. 30 of the 203 swarm events occurred within $\pm 5 \mathrm{~km}$ from the plate interface (Figure S4). Their lag time relative to the transient eastward GNSS displacements ranges from -73 to 23 days, with an average of -32 days and a standard deviation of 27 days. These lag times, particularly before the start of GNSS displacements, cannot be explained by SSE-induced stress loading and are instead more consistent with our speculation that earthquake swarms in the Hikurangi Trench are triggered by fluid migration.

Similar to the earthquake swarms, the tectonic tremors were often delayed with respect to the transient GNSS displacements caused by SSEs (Figures 12 and 13b). These delayed tremors might also be associated with SSE-induced fluid migration (Shaddox \& Schwartz, 2019) rather than SSE-induced stress loading. This is because the stress loading mechanism is inconsistent with the absence of tectonic tremor at the time of a transient GNSS displacement (Figures 12a and 12b). We did not observe any tremor bursts preceding a transient GNSS displacement by 5-25 days, which contrasts the earthquake swarm observations (Figure 9). Furthermore, the tremor counts 5-25 days before a transient GNSS displacement (147 events) are less than half of the tremor counts 5-25 days after a transient GNSS displacement (358 events; Figure 13b). It is unclear what causes such an asymmetric feature, although we speculate that tectonic tremors may be more sensitive to post-SSE fluid migration than pre-SSE fluid migration. It is necessary to precisely locate the delayed tremors to better understand their triggering mechanism and the cause of their asymmetric occurrence. Although tectonic tremors in other subduction zones, such as the Nankai Trough, southwest Japan (Shelly et al., 2006), occur along plate boundaries, it is still unclear whether tectonic tremors in the Hikurangi Trench are located along the plate boundary, in a fracture network within the upper plate, or within the subducting slab, due to large depth uncertainties (Todd et al., 2018). For delayed tremors located within the upper plate, the lag time between a given SSE and the tremors may reflect the time required for fluids to drain from intraslab faults to the upper plate.

\subsection{Comparison Between the Characteristics of Earthquake Swarms in the Hikurangi Trench and Other Subduction Zones}

Investigating the diversity of earthquake swarm activities among subduction zones is important because it reflects the diversity of relationships between seismicity and transient aseismic processes (i.e., fluid migration and SSEs) among subduction zones. In addition to the Hikurangi Trench and Boso-Oki region, earthquake swarms accompanying short-term (3 months or shorter) SSEs have been observed in the Japan (Ito et al., 2013; Kawasaki et al., 1995), Peru (Villegas-Lanza et al., 2016), and Ecuador trenches (Vallée et al., 2013). The earthquake swarms in the Japan and Peru trenches are interplate events. By contrast, most of the earthquake swarm events associated with the 2010 La Plata Island (central Ecuador) SSE were located dominotly within a subducted oceanic relief (Collot et al., 2017), although some of the swarm events could have ruptured the plate interface (Vallée et al., 2013). Unlike in the Hikurangi Trench, large lag time (e.g., 
more than several days) between SSEs and earthquake swarms has not been reported in the Japan, Peru, and Ecuador trenches. Regarding tectonic tremors, earthquake swarms neighboring a tremor-genic region have been observed in the Japan Trench (Nishikawa et al., 2019), as in the Hikurangi Trench. Contrastingly, no detectable tectonic tremors accompany earthquake swarms in the Peru and Ecuador trenches.

SSE-induced stress loading is a plausible triggering mechanism for earthquake swarms in the Japan (Ito et al., 2013) and Ecuador (Collot et al., 2017) trenches because SSEs and earthquake swarms coincide with each other. No pre- or post-SSE swarms have been reported in these subduction zones. In the Ecuador Trench, Collot et al. (2017) suggested that SSE-induced stress loading may have promoted microseismicity on preexisting faults within a subducted oceanic relief, which contrasts our preferred triggering mechanism for intraslab swarms in the Hikurangi Trench (i.e., fluid migration; Figure 14b). On the other hand, in the Peru Trench, because a large GNSS displacement due to the 2009 Bayovar Peninsula (northern Peru) SSE immediately followed an $M_{w} 5.8$ interplate earthquake (Villegas-Lanza et al., 2016), it is unclear whether the SSE triggered the earthquake swarm or the earthquake swarm triggered the SSE.

To the best of our knowledge, large lag times between short-term SSEs and accompanying earthquake swarms have been reported only in the Hikurangi Trench. We invoked intraplate fluid migration to explain these large lag times (Section 4.1). However, such intraplate fluid migration itself may be a common phenomenon among subduction zones (e.g., Otsubo et al., 2019), and it is unclear why pre- or post-SSE earthquake swarms have not been observed in other subduction zones. In order to verify our hypothesis (Section 4.1), it is also necessary to conduct detailed analyses focusing on the relationship between interplate SSEs and intraslab seismicity in other subduction zones.

On the other hand, there are subduction zones where neither interplate nor intraslab earthquake swarms accompany short-term SSEs (regardless of the depth of SSEs). Examples include the Nankai (Obara et al., 2004), Cascadia (Rogers \& Dragert, 2003), and Costa Rica (Outerbridge et al., 2010) subduction zones. These regions have a thing in common: the trench is filled with a thick ( $\geq 1 \mathrm{~km}$ ) sediment (Festa et al., 2018). The Hikurangi Trench, which lacks interplate earthquake swarms accompanying SSEs, is also characterized by a thick sediment environment $(\geq 2 \mathrm{~km})$. Based on these observations, we speculate that subduction zones with a thick sediment environment may tend to lack interplate earthquake swarms accompanying short-term SSEs. In such subduction zones, a thick sediment smooths the subducting seafloor. A simple interpretation is that subduction zones with smoothed subducting seafloor might have a homogeneous plate interface contact (Ruff, 1989) and lack the plate interface frictional heterogeneity that can produce small interplate earthquakes.

\subsection{Sensitivity of Our Earthquake Swarm Catalog to the Detection Criterion}

We checked the sensitivity of our earthquake swarm catalog to our earthquake swarm detection criterion. We classified a seismic sequence as a "potential earthquake swarm" (in Section 2.2) when the condition $\tau_{i+1}-\tau_{i}+1.5 \sigma<1$ was met for four or more successive events. This criterion is directly related to the probability of a false-positive earthquake swarm detection, which is $2.39 \times 10^{-3}$ for this criterion. In this section, we test two different criteria. The first criterion is that the condition $\tau_{i+1}-\tau_{i}+2 \sigma<1$ is met for four or more successive events. The second criterion is that the condition $\tau_{i+1}-\tau_{i}+1.5 \sigma<1$ is met for six or more successive events. Both criteria are stricter than the criterion used in Section 2.2, further suppressing the probability of a false-positive detection $\left(6.18 \times 10^{-4}\right.$ and $1.17 \times 10^{-4}$, respectively). Hereafter, we call these criteria the " $2 \sigma$ " and " 6 events" criteria, respectively.

We repeated our earthquake swarm detection using the above two criteria. We detected 56 and 34 earthquake swarm sequences during the 1997-2015 study period for the " $2 \sigma$ " and "6 events" criteria, respectively. This is 0.47 and 0.29 times the number of earthquake swarm sequences detected using the original criterion (Section 2.2) (119 sequences), respectively. The detected earthquake swarms were distributed along the east coast of the North Island (Figures S5 and S6), consistent with earlier results displayed in Figures 3b and 4. This indicates that the selected detection criterion does not strongly affect the spatial distribution of detected earthquake swarms. However, several of the earthquake swarm sequences that accompanied the SSEs detected by previous studies (Wallace \& Beavan, 2010; Wallace \& Eberhart-Phillips, 2013; Wallace 
et al., 2012, 2016) (colored stars in Figure 4) were not detected (see Figures S6), which suggests that the " $2 \sigma$ " and " 6 events" criteria are too strict for detecting the earthquake swarms associated with SSEs.

\subsection{Catalog Dependence of Our Earthquake Swarm Detection Results}

We compared the GeoNet earthquake catalog and the earthquake catalog developed by Yarce et al. (2019) to check the catalog dependence of our earthquake swarm detection results. Yarce et al. (2019) developed the catalog using data from both ocean-bottom seismometers and land seismometers from May 2014 through June 2015. Therefore, we expect this catalog has better completeness for offshore events than the GeoNet catalog. However, we found that 39 (91\%) of the $43 M \geq 3$ earthquakes in the Yarce et al. (2019) catalog have corresponding earthquakes in the GeoNet catalog. Only 4 (9\%) $M \geq 3$ earthquakes were newly detected by Yarce et al. (2019) from May 2014 through June 2015. Therefore, the difference between the GeoNet catalog and the Yarce et al. (2019) catalog for $M \geq 3$ earthquakes is small. We confirmed that incorporating the four newly detected $M \geq 3$ earthquakes to the GeoNet catalog does not change our earthquake swarm detection results.

To further check the catalog dependence of our earthquake swarm detection results, we repeated our earthquake swarm detection using only the Yarce et al. (2019) catalog. We estimated the magnitude of completeness for this catalog and found that the catalog is complete for $M 1.7$ or larger events. As a result, we detected 11 microearthquake swarm sequences (67 events) from May 2014 through June 2015 (Data Set S3). The detected microearthquake swarms are distributed along the eastern coast of the North Island (Figure S7), which is similar to the earthquake swarms detected using the GeoNet catalog (Figure 3b). We did not detect the swarm-like microseismicity near the subducting seamount off Gisborne $\left(38.8^{\circ} \mathrm{S}\right.$ and $\left.178.7^{\circ} \mathrm{E}\right)$ that had followed the September-October $2014 M_{w} 6.8$ Gisborne SSE (Shaddox \& Schwartz, 2019) because most of the microearthquakes are smaller than the magnitude of completeness for the Yarce et al. (2019) catalog (M 1.7).

In order to check the catalog dependence of the difference between the $b$-values for swarm events and nonswarm events (see Section 3.2 and Figure 5e), we tried to calculate the $b$-values using the Yarce et al. (2019) catalog. However, the small number of the detected microearthquake swarm events (67 events) prevented us from calculating a precise $b$-value for the microearthquake swarms. Although the estimated $b$-value for the microearthquake swarms $(0.96 \pm 0.12)$ is smaller than that of nonswarm events $(1.00 \pm 0.03)$, which is consistent with the $b$-values calculated using the GeoNet catalog (see Figure 5e), the difference is not significant because of the large uncertainty of the $b$-value for the microearthquake swarms.

\section{Conclusions}

We created a new earthquake swarm catalog for seismicity along the Hikurangi Trench for the 1997-2015 study period using the space-time ETAS model. The detected earthquake swarms were mainly distributed along the east coast of the North Island, with a sparse inland distribution; however, many tectonic tremors were located inland. Most of the detected earthquake swarms were intraplate events, and they repeatedly occurred in the same areas, suggesting the existence of characteristic intraplate structures that facilitate the recurrence of earthquake swarms.

Examining the earthquake swarm activity and GNSS data, we identified 23 possible new small SSEs. These small SSEs $\left(M_{w}\right.$ 5.6-6.4) are distributed close to the source regions of the previously identified large SSEs (Wallace \& Beavan, 2010; Wallace \& Eberhart-Phillips, 2013; Wallace et al., 2012, 2016). These small SSEs are important when discussing the slip budget along the northern and central Hikurangi Trench. Earthquake swarms sometimes preceded or succeeded transient GNSS displacements caused by SSEs by more than several days. SSE-induced stress loading is not a plausible triggering mechanism for the pre-SSE earthquake swarms because pre-SSE earthquake swarm activity ceased before the transient GNSS displacements occurred. We instead propose that intraplate fluid migration before and after the SSEs might have triggered the pre- and post-SSE earthquake swarms, respectively. This hypothesis is consistent with recent observations that suggest the accumulation and drainage of fluids within the subducting slab before and after an SSE, respectively, in the Hikurangi Trench (Shaddox \& Schwartz, 2019; Warren-Smith et al., 2019). Similar to earthquake swarms, tectonic tremors were sometimes delayed by more than several days relative to 
the transient GNSS displacements, implying a relationship between tectonic tremors and post-SSE fluid migration.

Our new earthquake swarm catalog is useful for future investigations of the heterogeneous seismogenic structures of the Hikurangi Trench. An important future research direction is the identification of the intraplate structures that facilitate the recurrence of earthquake swarms. These structures may be intraplate fluid conduits. Furthermore, our results suggest that there are complex relationships between seismicity, slow fault deformation processes, and the accumulation and drainage of intraplate fluids in the Hikurangi Trench. Further investigations of the interplay between these phenomena in the Hikurangi Trench and other subduction zones is essential to elucidate the underlying physics of seismicity and slow earthquakes.

\section{Data Availability Statement}

The GeoNet earthquake catalog and CMT solutions used in this study are available at https://www.geonet.org.nz/data/types/eq_catalogue. The GNSS time-series data are available at https://www.geonet.org. $\mathrm{nz} /$ data/types/geodetic. The tectonic tremor catalogs are from the supplementary information for Todd and Schwartz (2016), Todd et al. (2018), and Romanet and Ide (2019). The topography data (Smith \& Sandwell, 1997) are available at https://topex.ucsd.edu/marine_topo/. The slab geometry (Hayes, 2018) is available at https://www.sciencebase.gov/catalog/item/5aa1b00ee4b0b1c392e86467. The plate motion and plate boundary data (Bird, 2003) are from http://peterbird.name/publications/2003_PB2002/2003_PB2002. htm. The source code for the space-time ETAS model (Zhuang et al., 2002) is available at http://bemlar.ism. ac.jp/zhuang/software.html. The figures were prepared using the Generic Mapping Tools software package (Wessel et al., 2019), which is available at https://www.generic-mapping-tools.org.

\section{Acknowledgments}

This study was supported by JSPS KAKENHI (18J01056). We thank Dr. Wallace for providing the SSE catalog, which contains the SSEs listed in Wallace and Beavan (2010), Wallace et al. (2012), Wallace and Eberhart-Phillips (2013), and Wallace et al. (2016). We thank two anonymous reviewers for helpful comments.

\section{References}

Akaike, H. (1974). A new look at the statistical model identification. IEEE Transactions on Automatic Control, 19(6), 716-723. https://doi. org/10.1109/TAC.1974.1100705

Aki, K. (1965). Maximum likelihood estimate of $\mathrm{b}$ in the formula $\log \mathrm{N}=\mathrm{a}-\mathrm{bM}$ and its confidence limits. Bulletin of the Earthquake Research Institute, 43, 237-239.

Aoyama, H., Takeo, M., \& Ide, S. (2002). Evolution mechanisms of an earthquake swarm under the Hida Mountains, central Japan, in 1998. Journal of Geophysical Research, 107(B8), ESE-8. https://doi.org/10.1029/2001JB000540

Barker, D. H., Henrys, S., Caratori Tontini, F., Barnes, P. M., Bassett, D., Todd, E., \& Wallace, L. (2018). Geophysical constraints on the relationship between seamount subduction, slow slip, and tremor at the north Hikurangi subduction zone, New Zealand. Geophysical Research Letters, 45(23), 12-804. https://doi.org/10.1029/2018GL080259

Bell, R., Sutherland, R., Barker, D. H., Henrys, S., Bannister, S., Wallace, L., \& Beavan, J. (2010). Seismic reflection character of the Hikurangi subduction interface, New Zealand, in the region of repeated Gisborne slow slip events. Geophysical Journal International, 180(1), 34-48. https://doi.org/10.1111/j.1365-246X.2009.04401.x

Bird, P. (2003). An updated digital model of plate boundaries. Geochemistry, Geophysics, Geosystems, 4(3), 1027. https://doi. org/10.1029/2001GC000252

Collot, J. Y., Sanclemente, E., Nocquet, J. M., Leprêtre, A., Ribodetti, A., Jarrin, P., et al. (2017). Subducted oceanic relief locks the shallow megathrust in central Ecuador. Journal of Geophysical Research: Solid Earth, 122(5), 3286-3305. https://doi.org/10.1002/2016JB013849

Delahaye, E. J., Townend, J., Reyners, M. E., \& Rogers, G. (2009). Microseismicity but no tremor accompanying slow slip in the Hikurangi subduction zone, New Zealand. Earth and Planetary Science Letters, 277(1-2), 21-28. https://doi.org/10.1016/j.epsl.2008.09.038

Festa, A., Dilek, Y., Mittempergher, S., Ogata, K., Pini, G. A., \& Remitti, F. (2018). Does subduction of mass transport deposits (MTDs) control seismic behavior of shallow-level megathrusts at convergent margins? Gondwana Research, 60, 186-193. https://doi.org/10.1016/j. gr.2018.05.002

Fukuda, J. I. (2018). Variability of the space-time evolution of slow slip events off the Boso Peninsula, central Japan, from 1996 to 2014. Journal of Geophysical Research: Solid Earth, 123(1), 732-760. https://doi.org/10.1002/2017JB014709

Fukuda, J. I., Kato, A., Obara, K., Miura, S., \& Kato, T. (2014). Imaging of the early acceleration phase of the 2013-2014 Boso slow slip event. Geophysical Research Letters, 41(21), 7493-7500. https://doi.org/10.1002/2014GL061550

Gutenberg, B., \& Richter, C. F. (1944). Frequency of earthquakes in California. Bulletin of the Seismological Society of America, 34(4), $185-188$.

Hamling, I. J., Hreinsdóttir, S., Clark, K., Elliott, J., Liang, C., Fielding, E., et al. (2017). Complex multifault rupture during the 2016 Mw 7.8 Kaikōura earthquake, New Zealand. Science, 356(6334), eaam7194. https://doi.org/10.1126/science.aam7194

Hayes, G. (2018). Slab2 - a comprehensive subduction zone geometry model. U.S. Geological Survey Data Release. https://doi.org/10.5066/ F7PV6JNV

Holtkamp, S. G., \& Brudzinski, M. R. (2011). Earthquake swarms in circum-Pacific subduction zones. Earth and Planetary Science Letters, 305(1-2), 215-225. https://doi.org/10.1016/j.epsl.2011.03.004

Ito, Y., Hino, R., Suzuki, S., \& Kaneda, Y. (2013). Episodic slow slip events in the Japan subduction zone before the 2011 Tohoku-Oki earthquake. Tectonophysics, 600, 14-26. https://doi.org/10.1016/j.tecto.2012.08.022

Jacobs, K. M., Savage, M. K., \& Smith, E. C. G. (2016). Quantifying seismicity associated with slow slip events in the Hikurangi margin, New Zealand. New Zealand Journal of Geology and Geophysics, 59(1), 58-69. https://doi.org/10.1080/00288306.2015.1127827 
Kato, A., Obara, K., Igarashi, T., Tsuruoka, H., Nakagawa, S., \& Hirata, N. (2012). Propagation of slow slip leading up to the 2011 Mw 9.0 Tohoku-Oki earthquake. Science, 335(6069), 705-708. https://doi.org/10.1126/science.1215141

Kawasaki, I., Asai, Y., Tamura, Y., Sagiya, T., Mikami, N., Okada, Y., Sakata, M., et al. (1995). The 1992 Sanriku-oki, Japan, ultra-slow earthquake. Journal of Physics of the Earth, 43(2), 105-116. https://doi.org/10.4294/jpe1952.43.105

Liu, Y., Rice, J. R., \& Larson, K. M. (2007). Seismicity variations associated with aseismic transients in Guerrero, Mexico, 1995-2006. Earth and Planetary Science Letters, 262(3-4), 493-504. https://doi.org/10.1016/j.epsl.2007.08.018

Llenos, A. L., McGuire, J. J., \& Ogata, Y. (2009). Modeling seismic swarms triggered by aseismic transients. Earth and Planetary Science Letters, 281(1-2), 59-69. https://doi.org/10.1016/j.epsl.2009.02.011

Marsan, D., Reverso, T., Helmstetter, A., \& Enescu, B. (2013). Slow slip and aseismic deformation episodes associated with the subducting Pacific plate offshore Japan, revealed by changes in seismicity. Journal of Geophysical Research: Solid Earth, 118(9), 4900-4909. https:// doi.org/10.1002/jgrb.50323

Nishikawa, T., \& Ide, S. (2018). Recurring slow slip events and earthquake nucleation in the source region of the $M 7$ Ibaraki-Oki earthquakes revealed by earthquake swarm and foreshock activity. Journal of Geophysical Research: Solid Earth, 123(9), 7950-7968. https:// doi.org/10.1029/2018JB015642

Nishikawa, T., Matsuzawa, T., Ohta, K., Uchida, N., Nishimura, T., \& Ide, S. (2019). The slow earthquake spectrum in the Japan Trench illuminated by the S-net seafloor observatories. Science, 365(6455), 808-813. https://doi.org/10.1126/science.aax5618

Nishimura, T. (2014). Short-term slow slip events along the Ryukyu Trench, southwestern Japan, observed by continuous GNSS. Progress in Earth and Planetary Science, 1(1), 22. https://doi.org/10.1186/s40645-014-0022-5

Nishimura, T., Matsuzawa, T., \& Obara, K. (2013). Detection of short-term slow slip events along the Nankai Trough, southwest Japan, using GNSS data. Journal of Geophysical Research: Solid Earth, 118(6), 3112-3125. https://doi.org/10.1002/jgrb.50222

Obara, K., Hirose, H., Yamamizu, F., \& Kasahara, K. (2004). Episodic slow slip events accompanied by non-volcanic tremors in southwest Japan subduction zone. Geophysical Research Letters, 31(23), L23602. https://doi.org/10.1029/2004GL020848

Ogata, Y. (1988). Statistical models for earthquake occurrences and residual analysis for point processes. Journal of the American Statistical Association, 83(401), 9-27. https://doi.org/10.1080/01621459.1988.10478560

Ogata, Y. (2005). Detection of anomalous seismicity as a stress change sensor. Journal of Geophysical Research, 110, B05S06. https://doi. org/10.1029/2004JB003245

Okada, Y. (1985). Surface deformation due to shear and tensile faults in a half-space. Bulletin of the Seismological Society of America, 75(4), $1135-1154$.

Otsubo, M., Miyakawa, A., Katayama, I., \& Okazaki, K. (2019). An inhomogeneous across-slab conduit controlled by intraslab stress heterogeneity in the Nankai subduction zone. Scientific Reports, 9, 994. https://doi.org/10.1038/s41598-018-38142-w

Outerbridge, K. C., Dixon, T. H., Schwartz, S.Y., Walter, J.I., Protti, M., Gonzalez, V., et al. (2010). A tremor and slip event on the Cocos-Caribbean subduction zone as measured by a global positioning system (GPS) and seismic network on the Nicoya Peninsula, Costa Rica. Journal of Geophysical Research, 115(B10), B10408. https://doi.org/10.1029/2009JB006845

Ozawa, S., Miyazaki, S., Hatanaka, Y., Imakiire, T., Kaidzu, M., \& Murakami, M. (2003). Characteristic silent earthquakes in the eastern part of the Boso peninsula, central Japan. Geophysical Research Letters, 30(6), 1283. https://doi.org/10.1029/2002GL016665

Petersen, T., Gledhill, K., Chadwick, M., Gale, N. H., \& Ristau, J. (2011). The New Zealand national seismograph network. Seismological Research Letters, 82(1), 9-20. https://doi.org/10.1785/gssrl.82.1.9

Raleigh, C. B., Healy, J. H., \& Bredehoeft, J. D. (1976). An experiment in earthquake control at Rangely, Colorado. Science, 191(4233), 1230-1237. https://doi.org/10.1126/science.191.4233.1230

Reverso, T., Marsan, D., \& Helmstetter, A. (2015). Detection and characterization of transient forcing episodes affecting earthquake activity in the Aleutian Arc system. Earth and Planetary Science Letters, 412, 25-34. https://doi.org/10.1016/j.epsl.2014.12.012

Rivet, D., Campillo, M., Shapiro, N. M., Cruz-Atienza, V., Radiguet, M., Cotte, N., \& Kostoglodov, V. (2011). Seismic evidence of nonlinear crustal deformation during a large slow slip event in Mexico. Geophysical Research Letters, 38(8), L08308. https://doi. org/10.1029/2011GL047151

Rogers, G., \& Dragert, H. (2003). Episodic tremor and slip on the Cascadia subduction zone: The chatter of silent slip. Science, 300(5627), 1942-1943. https://doi.org/10.1126/science.1084783

Romanet, P., \& Ide, S. (2019). Ambient tectonic tremors in Manawatu, Cape Turnagain, Marlborough, and Puysegur, New Zealand. Earth Planets and Space, 71(1), 1-9. https://doi.org/10.1186/s40623-019-1039-1

Ruff, L. J. (1989). Do trench sediments affect great earthquake occurrence in subduction zones? Pure and Applied Geophysics, 129, 263-282. https://doi.org/10.1007/BF00874629

Shaddox, H. R., \& Schwartz, S. Y. (2019). Subducted seamount diverts shallow slow slip to the forearc of the northern Hikurangi subduction zone, New Zealand. Geology, 47(5), 415-418. https://doi.org/10.1130/G45810.1

Shelly, D. R., Beroza, G. C., Ide, S., \& Nakamula, S. (2006). Low-frequency earthquakes in Shikoku, Japan, and their relationship to episodic tremor and slip. Nature, 442(7099), 188-191. https://doi.org/10.1038/nature04931

Smith, W. H., \& Sandwell, D. T. (1997). Global sea floor topography from satellite altimetry and ship depth soundings. Science, 277(5334), 1956-1962. https://doi.org/10.1126/science.277.5334.1956

Socquet, A., Valdes, J.P., Jara, J., Cotton, F., Walpersdorf, A., Cotte, A., et al. (2017). An 8 month slow slip event triggers progressive nucleation of the 2014 Chile megathrust. Geophysical Research Letters, 44(9), 4046-4053. https://doi.org/10.1002/2017GL073023

Tenthorey, E., Cox, S. F., \& Todd, H. F. (2003). Evolution of strength recovery and permeability during fluid-rock reaction in experimental fault zones. Earth and Planetary Science Letters, 206(1-2), 161-172. https://doi.org/10.1016/S0012-821X(02)01082-8

Todd, E. K., \& Schwartz, S. Y. (2016). Tectonic tremor along the northern Hikurangi Margin, New Zealand, between 2010 and 2015. Journal of Geophysical Research: Solid Earth, 121(12), 8706-8719. https://doi.org/10.1002/2016JB013480

Todd, E. K., Schwartz, S. Y., Mochizuki, K., Wallace, L. M., Sheehan, A. F., Webb, S.C., et al. (2018). Earthquakes and tremor linked to seamount subduction during shallow slow slip at the Hikurangi margin, New Zealand. Journal of Geophysical Research: Solid Earth, 123(8), 6769-6783. https://doi.org/10.1029/2018JB016136

Tsuneishi, Y., \& Nakamura, K. (1970). Faulting associated with the Matsushiro swarm earthquakes. Bulletin of the Earthquake Research Institute, 48, 29-51.

Vallée, M., Nocquet, J. M., Battaglia, J., Font, Y., Segovia, M., Régnier, M., et al. (2013). Intense interface seismicity triggered by a shallow slow slip event in the Central Ecuador subduction zone. Journal of Geophysical Research: Solid Earth, 118(6), 2965-2981. https://doi. org/10.1002/jgrb.50216

Vidale, J. E., \& Shearer, P. M. (2006). A survey of 71 earthquake bursts across southern California: Exploring the role of pore fluid pressure fluctuations and aseismic slip as drivers. Journal of Geophysical Research, 111, B05312. https://doi.org/10.1029/2005JB004034 
Villegas-Lanza, J. C., Nocquet, J.-M., Rolandone, F., Vallée, M., Tavera, H., Bondoux, F., et al. (2016). A mixed seismic-aseismic stress release episode in the Andean subduction zone. Nature Geoscience, 9(2), 150-154. https://doi.org/10.1038/ngeo2620

Waite, G. P., \& Smith, R. B. (2002). Seismic evidence for fluid migration accompanying subsidence of the Yellowstone caldera. Journal of Geophysical Research, 107(B9), ESE-1. https://doi.org/10.1029/2001JB000586

Wallace, L. M. (2020). Slow slip events in New Zealand. Annual Review of Earth and Planetary Sciences, 48, 175-203. https://doi. org/10.1146/annurev-earth-071719-055104

Wallace, L. M., \& Beavan, J. (2010). Diverse slow slip behavior at the Hikurangi subduction margin, New Zealand. Journal of Geophysical Research, 115(B12), B12402. https://doi.org/10.1029/2010JB007717

Wallace, L. M., Beavan, J., Bannister, S., \& Williams, C. (2012). Simultaneous long-term and short-term slow slip events at the Hikurangi subduction margin, New Zealand: Implications for processes that control slow slip event occurrence, duration, and migration. Journal of Geophysical Research, 117(B11), B11402. https://doi.org/10.1029/2012JB009489

Wallace, L. M., \& Eberhart-Phillips, D. (2013). Newly observed, deep slow slip events at the central Hikurangi margin, New Zealand: Implications for downdip variability of slow slip and tremor, and relationship to seismic structure. Geophysical Research Letters, 40(20), 5393-5398.

Wallace, L. M., Kaneko, Y., Hreinsdóttir, S., Hamling, I., Peng, Z., Bartlow, N., et al. (2017). Large-scale dynamic triggering of shallow slow slip enhanced by overlying sedimentary wedge. Nature Geoscience, 10(10), 765-770. https://doi.org/10.1038/ngeo3021

Wallace, L. M., Webb, S. C., Ito, Y., Mochizuki, K., Hino, R., Henrys, S., et al. (2016). Slow slip near the trench at the Hikurangi subduction zone, New Zealand. Science, 352(6286), 701-704. https://doi.org/10.1126/science.aaf2349

Warren-Smith, E., Fry, B., Wallace, L., Chon, E., Henrys, S., Sheehan, A., et al. (2019). Episodic stress and fluid pressure cycling in subducting oceanic crust during slow slip. Nature Geoscience, 12(6), 475-481. https://doi.org/10.1038/s41561-019-0367-x

Wessel, P., Luis, J. F., Uieda, L., Scharroo, R., Wobbe, F., Smith, W. H. F., \& Tian, D. (2019). The Generic Mapping Tools version 6. Geochem istry, Geophysics, Geosystems, 20, 5556-5564. https://doi.org/10.1029/2019GC008515

Wiemer, S., \& Wyss, M. (2000). Minimum magnitude of completeness in earthquake catalogs: Examples from Alaska, the western United States, and Japan. Bulletin of the Seismological Society of America, 90(4), 859-869. https://doi.org/10.1785/0119990114

Woessner, J., \& Wiemer, S. (2005). Assessing the quality of earthquake catalogues: Estimating the magnitude of completeness and its uncertainty. Bulletin of the Seismological Society of America, 95(2), 684-698. https://doi.org/10.1785/0120040007

Yamashita, T. (1998). Simulation of seismicity due to fluid migration in a fault zone. Geophysical Journal International, 132(3), 674-686. https://doi.org/10.1046/j.1365-246X.1998.00483.x

Yarce, J., Sheehan, A. F., Nakai, J S., Schwartz, S. Y., Mochizuki, K., Savage, M. K., et al. (2019). Seismicity at the northern Hikurangi Margin, New Zealand, and investigation of the potential spatial and temporal relationships with a shallow slow slip event. Journal of Geophysical Research: Solid Earth, 124(5), 4751-4766. https://doi.org/10.1029/2018JB017211

Yoshida, K., Saito, T., Emoto, K., Urata, Y., \& Sato, D. (2019). Rupture directivity, stress drop, and hypocenter migration of small earthquakes in the Yamagata-Fukushima border swarm triggered by upward pore-pressure migration after the 2011 Tohoku-Oki earthquake. Tectonophysics, 769, 228184. https://doi.org/10.1016/j.tecto.2019.228184

Zhuang, J., Ogata, Y., \& Vere-Jones, D. (2002). Stochastic declustering of space-time earthquake occurrences. Journal of the American Statistical Association, 97(458), 369-380. https://doi.org/10.1198/016214502760046925 